\title{
A new analysis method for polymer-confined concrete columns
}

1 Y. Ouyang BEng, MPhil, PhD Graduate Engineer, Hsin Chong Group Holdings Limited, Hong Kong

2 S. H. Lo BSC(Eng), MPhil, Dr-Ing., FHKIE, SMIEEE Professor, Department of Civil Engineering, The University of Hong Kong, Hong Kong

3 A. K. H. Kwan $B S C(E n g), P h D, M I C E, C E n g, F H K I E, R P E$ Professor, Department of Civil Engineering, The University of Hong Kong, Hong Kong
4 J. C. M. Ho BEng, MPhil, PhD, MHKIE, MIEAust, CPEng, NER, MIStructE, CEng

Senior Lecturer, School of Civil Engineering, The University of Queensland, Brisbane, Australia (corresponding author: johnny.ho@uq.edu.au)
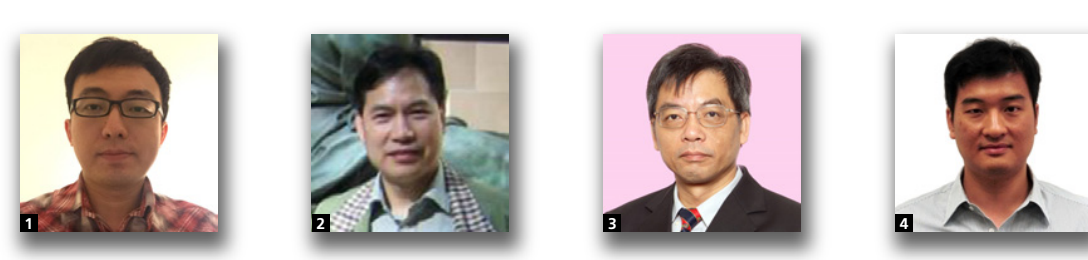

The confining stresses in a concrete column confined with fibre-reinforced polymer (FRP) are uniform across the section and isotropic only when the column is under concentric loading and circular in shape. If the column is under eccentric loading or non-circular in shape, the confining stresses in the column become non-uniform and anisotropic. However, without knowing the confining stresses, it is impossible to predict the structural behaviour of confined concrete columns. To overcome this difficulty, a new finite-element (FE) method was developed based on the most up-to-date lateral strain-axial strain and axial stress-strain constitutive models of concrete. This paper reports on using the method to analyse circular concrete columns confined by FRP under eccentric loading. It was found that, under eccentric loading, the confining stresses are generally smaller at larger eccentricity. Overall, good agreement between the theoretical results and published experimental data was achieved. In theory, the FE method can be applied to concrete columns of any shape and even those provided with lateral reinforcement, as will be elaborated upon in subsequent papers.

\section{Notation}

A strain transformation matrix

$A_{\mathrm{c}} \quad$ total area of concrete cross-section

$A_{i} \quad$ area of concrete element $i$

B strain-displacement matrix

C constitutive matrix

$c \quad$ neutral axis depth

$d \quad$ effective depth

$d_{\mathrm{e}} \quad$ eccentricity of axial load

$E_{\mathrm{c}} \quad$ elastic modulus of concrete

e out-of-roundness parameter

$f_{\mathrm{c}} \quad$ unconfined concrete strength

$f_{\text {cc }} \quad$ confined concrete stress

$f_{\mathrm{cc}}^{\prime} \quad$ confined concrete stress taking into account strain gradient

$f_{\mathrm{r}} \quad$ confining concrete stress

$f_{\mathrm{r} \text {,avg }} \quad$ average confining stress

$f_{\mathrm{t}} \quad$ uniaxial tensile strength

\begin{tabular}{|c|c|}
\hline$J_{3}$ & third deviatoric stress invariant \\
\hline$M_{x}$ & moment about $x$-axis \\
\hline$M_{y}$ & moment about $y$-axis \\
\hline$n$ & total number of concrete elements \\
\hline$P$ & axial load \\
\hline$P_{\mathrm{FE}}$ & $\begin{array}{l}\text { maximum predicted load by finite-element (FE) } \\
\text { analysis }\end{array}$ \\
\hline$P_{\text {FE-I }}$ & $\begin{array}{l}\text { maximum predicted load by FE analysis using } 2203 \\
\text { elements }\end{array}$ \\
\hline$P_{\mathrm{FE}-\mathrm{II}}$ & $\begin{array}{l}\text { maximum predicted load by FE analysis using } 6718 \\
\text { elements }\end{array}$ \\
\hline$t_{\mathrm{f}}$ & thickness of FRP \\
\hline $\boldsymbol{u}$ & displacement vector \\
\hline$x_{\mathrm{p}}$ & $x$-coordinate of eccentric load \\
\hline$y_{\mathrm{p}}$ & $y$-coordinate of eccentric load \\
\hline$\gamma_{12}$ & $\begin{array}{l}\text { shear strain in the plane defined by directions } 1 \\
\text { and } 2\end{array}$ \\
\hline & lateral strain in principal direction 1 \\
\hline
\end{tabular}


lateral strain in principal direction 2

$\varepsilon_{3} \quad$ axial strain in direction 3

$\varepsilon_{\mathrm{c}} \quad$ axial strain in concrete

$\varepsilon_{\mathrm{cc}} \quad$ axial strain at peak stress of confined concrete

$\varepsilon_{\text {co }} \quad$ axial strain at peak stress of unconfined concrete

$\varepsilon^{\mathrm{e}} \quad$ elastic component of lateral strain

$\varepsilon^{\mathrm{p}} \quad$ inelastic component of lateral strain

$\varepsilon_{3,1}^{o} \quad$ threshold value of axial strain $\varepsilon_{3}$ before splitting

cracks occur in direction 1

$\varepsilon_{3,2}^{\mathrm{o}} \quad$ threshold value of axial strain $\varepsilon_{3}$ before splitting

cracks occur in direction 2

$\lambda \quad E_{\mathrm{c}} /\left[\left(1+v_{\mathrm{c}}\right)\left(1-2 v_{\mathrm{c}}\right)\right]$

$v_{\mathrm{c}} \quad$ Poisson's ratio of concrete

$\sigma \quad$ stress vector

$\sigma_{1} \quad$ confining stress in direction 1

$\sigma_{2} \quad$ confining stress in direction 2

$\sigma_{3} \quad$ axial stress in direction 3

$\sigma_{\mathrm{c}} \quad$ axial concrete stress

$\sigma_{\mathrm{sz}} \quad$ axial stress of steel tube

$\tau_{12} \quad$ shear stress in the plane defined by directions 1 and 2

$\omega_{x} \quad$ bi-curvature about $x$-axis

$\omega_{y} \quad$ bi-curvature about $y$-axis

\section{Introduction}

Recent studies have shown that the performance of concrete columns can be significantly boosted by adding external fibrereinforced polymer (FRP) confinement (Hu, 2013; Lam and Teng, 2002; Ozbakkaloglu et al., 2013). As the concrete in a FRP-confined column expands laterally when subjected to axial compression, the FRP confinement restrains the lateral expansions and thereby produces confining stresses in the concrete. The concrete column is thus under triaxial compression and both the strength and ductility of the concrete column would be significantly increased. The increases in strength and ductility are highly dependent on the actual confining stresses developed at various stages of loading, which in turn are dependent on the stiffness of the FRP confinement and the lateral strain-axial strain constitutive relation of the concrete (Fam and Rizkalla, 2001; Harries and Kharel, 2002; Mirmiran and Shahawy, 1997; Teng et al., 2007). Particularly, after cracking, the concrete would increase in volume albeit subjected to triaxial compression (Imran and Pantazopoulou, 1996), leading to substantially larger lateral expansions and confining stresses at the inelastic stage. However, the lateral expansions and confining stresses are inter-related and therefore not easy to determine for an analysis of the structural behaviour of FRP-confined concrete columns.

Even with the confining stresses at various stages of loading determined, an axial stress-strain constitutive model for confined concrete under given confining stresses is needed to evaluate the axial behaviour of a FRP-confined column.
A number of axial stress-strain constitutive models have been developed. Among them, the one developed by Mander et al. (1988), based on the pioneering work of Popovics (1973), is probably the most practical. This model has been widely adopted to analyse FRP-confined concrete (Fam and Rizkalla, 2001; Jiang and Teng, 2007; Saadatmanesh et al., 1994; Teng et al., 2007) but is only applicable to normal-strength concrete. In contrast, a later model developed by Attard and Setunge (1996), based on the test results of concrete cylinders under active confinement, is applicable to a much wider range of concrete strength, covering both normal- and high-strength concretes. It is interesting to note that the classical but rather old model developed by Saenz (1964) has also been modified for application to concrete confined by steel tubes ( $\mathrm{Hu}$ et al., 2003).

After extensive studies on the axial stress-strain behaviour of FRP-confined concrete, many axial stress-strain models for FRP-confined concrete have been developed. These models may be classified into design-oriented models and analysisoriented models (Teng and Lam, 2004). The design-oriented models give closed-form axial stress-strain curves in terms of certain design parameters and are therefore relatively easy to use in practical design applications. They are developed based on test results of circular columns under concentric loading. No reference is made to the confining stresses whatsoever and thus the variation of the confining stresses during loading is not traceable. On the other hand, the analysis-oriented models require the use of an incremental iterative numerical procedure to trace the development of confining stresses for axial stressstrain analysis. They are not suitable for hand or spreadsheet calculations and thus demand computer analysis, but should be more rigorous and accurate. However, a uniform and isotropic distribution of confining stresses across the concrete section is assumed and therefore these so-called analysis-oriented models are applicable only to circular columns under concentric loading.

To deal with cases in which the confining stresses could be non-uniform or anisotropic, such as columns subjected to eccentric loading or with non-circular shape, a more general analytical method, such as the finite-element (FE) method, is needed. However, the FE analysis of confined concrete is not without problems. Mirmiran et al. (2000) used the Drucker-Prager failure surface and non-associated flow rule in the Ansys environment to analyse the non-linear behaviour of concentrically loaded FRP-confined circular concrete columns. They obtained theoretical axial stress-strain curves in good agreement with the experimental counterparts, but lateral strains significantly different from the experimental results. Similarly, Yu et al. (2010a, 2010b) used the extended Drucker-Prager failure surface and non-associated flow rule in the Abaqus environment to conduct FE analysis of concentrically loaded FRP-confined circular and non-circular concrete columns. For non-circular columns, they either 
treated the non-circular section as an equivalent circular section or replaced the anisotropic confining stresses at each point by equivalent isotropic confining stresses. They also obtained theoretical axial stress-strain curves in good agreement with the experimental counterparts. However, it has been found necessary to use certain solution-dependent field variables in the flow rule to ensure that the lateral strains would vary with the axial strain according to the constitutive models established from experimental results (Tao et al., 2013).

A new FE method for the analysis of FRP-confined concrete columns is proposed in this paper. Non-uniform and anisotropic confining stresses are allowed so as to deal with the general case of circular or non-circular columns under eccentric loading. In the analysis, the axial strain is applied incrementally to the section in the form of prescribed axial strain at the loading point with plane sections assumed to remain plane after loading. For determination of the biaxial lateral strains at each point within the section, the lateral strain-axial strain constitutive model developed by Dong et al. (2015a) is employed. The inelastic components of the biaxial lateral strains so evaluated are treated as residual strains and the biaxial confining stresses are then determined by twodimensional (2D) FE analysis. Finally, the axial stress at each point within the section is determined using the $3 \mathrm{D}$ failure surface developed by Menétrey and Willam (1995), the axial stress-strain constitutive model developed by Attard and Setunge (1996) and the strain gradient model developed by Ho and Peng (2013). To verify its applicability and accuracy, the proposed FE method is used to analyse FRP-confined circular concrete columns under eccentric loading tested by previous researchers.

\section{Constitutive modelling of concrete under triaxial stresses}

When a FRP-confined concrete column is subjected to eccentric loading, the lateral strains and confining stresses are anisotropic. Hence, at each point, there are two lateral strains and two confining stresses, as shown in Figure 1. Here, the coordinate axes in the two in-plane principal directions are taken as directions 1 and 2, whereas the coordinate axis in the out-of-plane principal direction (the axial direction) is taken as direction 3. Following this coordinate system, the lateral strains in directions 1 and 2 are denoted by $\varepsilon_{1}$ and $\varepsilon_{2}$, respectively, and the axial strain in direction 3 is denoted by $\varepsilon_{3}$. Likewise, the confining stresses in directions 1 and 2 are denoted by $\sigma_{1}$ and $\sigma_{2}$, respectively, and the axial stress in direction 3 is denoted by $\sigma_{3}$.

The confining stresses $\sigma_{1}$ and $\sigma_{2}$ are to be evaluated by 2D FE analysis taking into account the in-plane stress-strain relation of the concrete and the stress-strain relation of the confining material. Then, the axial strength of the concrete in each concrete element with confining stresses $\sigma_{1}$ and $\sigma_{2}$

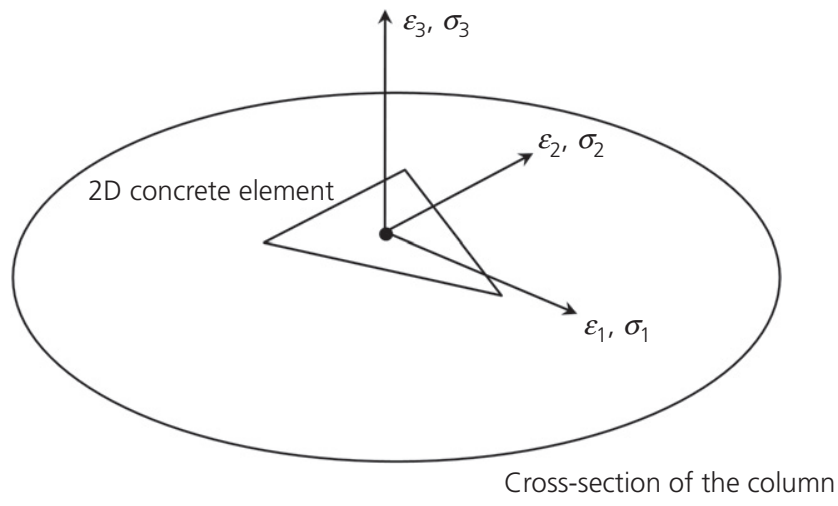

Figure 1. Definition of coordinate axes

applied can be determined from the triaxial failure surface of the concrete. Having determined the axial strength, the axial stress $\sigma_{3}$ developed in each concrete element can be evaluated by applying the axial stress-strain constitutive model and the strain gradient model. Finally, by integrating the axial stresses in all the concrete elements over the concrete section and their respective bending moments about the coordinate axes, the total axial force and bending moments can be evaluated.

The constitutive modelling of concrete in the above analysis consists of four parts - the lateral strain-axial strain constitutive model, the triaxial failure surface, the axial stress-strain constitutive model and the strain gradient model, which are now presented in turn in the following sections.

\subsection{Lateral strain-axial strain constitutive model}

At elastic range, concrete subjected to axial compression undergoes lateral expansions at a constant rate due to the Poisson's ratio effect. Beyond a certain compressive strain limit, splitting cracks start to develop and lateral expansions increase with compressive strain at an increasing rate (Imran and Pantazopoulou, 1996). The lateral strains are dependent on the axial strain, confining stress and concrete strength. Dong et al. (2015a) recently developed a constitutive model for predicting the lateral strains of confined concrete by analysing published test results. In this constitutive model, the two lateral strains $\varepsilon_{1}$ and $\varepsilon_{2}$ are each divided into two components - an elastic component arising from the Poisson's ratio effect and an inelastic component arising from the formation of splitting cracks. In other words, $\varepsilon_{1}=\varepsilon_{1}^{\mathrm{e}}+\varepsilon_{1}^{\mathrm{p}}$ and $\varepsilon_{2}=\varepsilon_{2}^{\mathrm{e}}+\varepsilon_{2}^{\mathrm{p}}$, in which $\varepsilon_{1}^{\mathrm{e}}$ and $\varepsilon_{2}^{\mathrm{e}}$ are the elastic components and $\varepsilon_{1}^{\mathrm{p}}$ and $\varepsilon_{2}^{\mathrm{p}}$ are the inelastic components. It is noted that the model has been verified by several previous theoretical studies on axially loaded FRP-confined concrete columns with circular and rectangular sections (Dong et al., 2015b; Kwan et al., 2015; Lo et al., 2015). 
The elastic components $\varepsilon_{1}^{\mathrm{e}}$ and $\varepsilon_{2}^{\mathrm{e}}$ are linear functions of $\varepsilon_{3}$, $\sigma_{1}$ and $\sigma_{2}$, and can be obtained by linear elasticity theory as

1a. $\varepsilon_{1}^{\mathrm{e}}=-v_{\mathrm{c}} \varepsilon_{3}+\left(1-v_{\mathrm{c}}^{2}\right) \frac{\sigma_{1}}{E_{\mathrm{c}}}-v_{\mathrm{c}}\left(1+v_{\mathrm{c}}\right) \frac{\sigma_{2}}{E_{\mathrm{c}}}$

1b. $\quad \varepsilon_{2}^{\mathrm{e}}=-v_{\mathrm{c}} \varepsilon_{3}+\left(1-v_{\mathrm{c}}^{2}\right) \frac{\sigma_{2}}{E_{\mathrm{c}}}-v_{\mathrm{c}}\left(1+v_{\mathrm{c}}\right) \frac{\sigma_{1}}{E_{\mathrm{c}}}$

in which $v_{\mathrm{c}}$ and $E_{\mathrm{c}}$ are the Poisson's ratio and Young's modulus of the concrete, respectively. Before the concrete cracks, these elastic lateral strains are the only lateral strains.

When the axial strain $\varepsilon_{3}$ exceeds the threshold value $\varepsilon_{3,1}^{o}$, splitting cracks would be formed in direction 1 , and when the axial strain $\varepsilon_{3}$ exceeds the threshold value $\varepsilon_{3,2}^{o}$, splitting cracks would be formed in direction 2. Based on analysis of the published test results, the threshold values $\varepsilon_{3,1}^{\mathrm{o}}$ and $\varepsilon_{3,2}^{\mathrm{o}}$ are given by

2a.

$$
\varepsilon_{3,1}^{\mathrm{o}}=\varepsilon_{\mathrm{co}}\left(0.44+0.0021 f_{\mathrm{c}}-0.00001 f_{\mathrm{c}}^{2}\right)
$$$$
\times\left[1+30 \exp \left(-0 \cdot 013 f_{\mathrm{c}}\right) \frac{\sigma_{1}}{f_{\mathrm{c}}}\right]
$$

$2 b$.

$$
\begin{aligned}
\varepsilon_{3,2}^{\mathrm{o}}= & \varepsilon_{\mathrm{co}}\left(0 \cdot 44+0 \cdot 0021 f_{\mathrm{c}}-0 \cdot 00001 f_{\mathrm{c}}^{2}\right) \\
& \times\left[1+30 \exp \left(-0 \cdot 013 f_{\mathrm{c}}\right) \frac{\sigma_{2}}{f_{\mathrm{c}}}\right]
\end{aligned}
$$

where $f_{\mathrm{c}}$ is the unconfined compressive strength of the concrete (this may be taken as the cylinder strength of the concrete) and $\varepsilon_{\mathrm{co}}$ is the axial strain corresponding to the unconfined compressive strength of the concrete. Based on analysis of the published test results, the inelastic components $\varepsilon_{1}^{p}$ and $\varepsilon_{2}^{p}$ are given by

$$
\varepsilon_{1}^{\mathrm{p}}=19 \cdot 1\left(\varepsilon_{3}-\varepsilon_{3,1}^{\mathrm{o}}\right)^{1 \cdot 5}
$$

$$
\times\left\{0 \cdot 1+0 \cdot 9\left[\exp \left(-5 \cdot 3\left(\frac{\sigma_{1}}{f_{\mathrm{c}}}\right)^{1 \cdot 1}\right)\right]\right\}
$$

$$
\varepsilon_{2}^{\mathrm{p}}=19 \cdot 1\left(\varepsilon_{3}-\varepsilon_{3,2}^{\mathrm{o}}\right)^{1 \cdot 5}
$$

$3 b$.

$$
\times\left\{0 \cdot 1+0 \cdot 9\left[\exp \left(-5 \cdot 3\left(\frac{\sigma_{2}}{f_{\mathrm{c}}}\right)^{1 \cdot 1}\right)\right]\right\}
$$

The lateral strains and the confining stresses are thus interrelated. By combining Equations 1a, 1b, 3a and $3 \mathrm{~b}$ and expressing them in matrix form, the following constitutive equation at element level is obtained

4.

$$
\begin{aligned}
\left\{\begin{array}{c}
\sigma_{1} \\
\sigma_{2} \\
\tau_{12}
\end{array}\right\}= & \lambda\left[\begin{array}{ccc}
1-v_{\mathrm{c}} & v_{\mathrm{c}} & 0 \\
v_{\mathrm{c}} & 1-v_{\mathrm{c}} & 0 \\
0 & 0 & \left(1-v_{\mathrm{c}}\right) / 2
\end{array}\right] \\
& \times\left\{\begin{array}{c}
\varepsilon_{1}-\varepsilon_{1}^{\mathrm{p}} \\
\varepsilon_{2}-\varepsilon_{2}^{\mathrm{p}} \\
\gamma_{12}
\end{array}\right\}+\lambda v_{\mathrm{c}}\left\{\begin{array}{c}
\varepsilon_{3} \\
\varepsilon_{3} \\
0
\end{array}\right\}
\end{aligned}
$$

where $\lambda=E_{\mathrm{c}} /\left[\left(1+v_{\mathrm{c}}\right)\left(1-2 v_{\mathrm{c}}\right)\right]$. Since the inelastic components $\varepsilon_{1}^{\mathrm{p}}$ and $\varepsilon_{2}^{\mathrm{p}}$ are dependent on the axial strain $\varepsilon_{3}$, they have to be computed at each loading step.

\subsection{Triaxial failure surface of concrete}

The Drucker-Prager failure surface employed by Mirmiran et al. (2000) has the limitation that it is applicable only when the two confining stresses $\sigma_{1}$ and $\sigma_{2}$ are equal. In general, $\sigma_{1}$ and $\sigma_{2}$ may not be equal and the presence of the third deviatoric stress invariant $J_{3}$ could result in a lower axial strength of the concrete. To avoid over-estimating the axial strength due to omission of the third deviatoric stress invariant, $\mathrm{Yu}$ et al. (2010a, 2010b) used the extended Drucker-Prager failure surface with the third deviatoric stress invariant incorporated. However, the $K$ value in the extended Drucker-Prager failure surface was restricted to between 0.778 and 1.0 to ensure convexity of the yield surface, and such a restriction would still lead to over-estimation of the axial strength when $\sigma_{1}$ and $\sigma_{2}$ are unequal. To overcome such a difficulty, therefore, the failure surface proposed by Menétrey and Willam (1995) is adopted here.

According to Menétrey and Willam (1995), the failure surface of concrete under triaxial compression is described by

5. $\quad F(\xi, \rho, \theta)=\left(\sqrt{1 \cdot 5} \frac{\rho}{f_{\mathrm{c}}}\right)^{2}+m\left[\frac{\rho}{\sqrt{6} f_{\mathrm{c}}} r(\theta, e)+\frac{\xi}{\sqrt{3} f_{\mathrm{c}}}\right]$

$$
-c=0
$$

in which

6a. $\quad \xi=\frac{I_{1}}{\sqrt{3}} ; \quad I_{1}=\sigma_{1}+\sigma_{2}+f_{\mathrm{cc}}$

$6 b$.

$$
\begin{aligned}
\rho= & \sqrt{2 J_{2}} ; \quad J_{2}=\frac{1}{6}\left[\left(\sigma_{1}-\sigma_{2}\right)^{2}\right. \\
& \left.+\left(\sigma_{2}-f_{\mathrm{cc}}\right)^{2}+\left(f_{\mathrm{cc}}-\sigma_{1}\right)^{2}\right]
\end{aligned}
$$




$$
\text { 6c. } \quad \begin{aligned}
\theta & =\frac{1}{3} \cos ^{-1}\left(\frac{3 \sqrt{3} J_{3}}{2 J_{2}^{2 / 3}}\right) ; \\
J_{3} & =\left(\sigma_{1}-\frac{I_{1}}{3}\right) \cdot\left(\sigma_{2}-\frac{I_{1}}{3}\right) \cdot\left(f_{\mathrm{cc}}-\frac{I_{1}}{3}\right)
\end{aligned}
$$

6d. $\quad m=3 \frac{f_{\mathrm{c}}^{2}-f_{\mathrm{t}}^{2}}{f_{\mathrm{c}} f_{\mathrm{t}}} \cdot \frac{e}{e+1}$ in terms of the other variables, an iterative numerical procedure has to be employed to determine the value of $f_{\text {cc. }}$. First, an initial estimate of $f_{\mathrm{cc}}$ is taken as $f_{\mathrm{c}}$. Then, the estimate of $f_{\mathrm{cc}}$ is successively adjusted by small changes until Equation 5 is satisfied. At each iteration step, the rate of change of $F$ $(\xi, \rho, \theta)$ with $f_{\mathrm{cc}}$ is estimated and the small change in $f_{\mathrm{cc}}$ to be applied so that $F(\xi, \rho, \theta)$ would become zero is calculated accordingly. In practice, this iterative procedure converges quite quickly.

6e. $\quad r(\theta, e)=\frac{4\left(1-e^{2}\right) \cos ^{2} \theta+(2 e-1)^{2}}{2\left(1-e^{2}\right) \cos \theta+(2 e-1)\left[4\left(1-e^{2}\right) \cos ^{2} \theta+5 e^{2}-4 e\right]^{1 / 2}}$

where $f_{\mathrm{cc}}$ is the confined concrete strength, $f_{\mathrm{t}}$ is the uniaxial tensile strength and $e$ is the out-of-roundness parameter. As recommended by Papanikolaou and Kappos (2007), the parameter $e$ is evaluated by assuming that the ratio between the biaxial compressive strength $f_{\mathrm{bc}}$ (the compressive strength when either $\sigma_{1}=0$ or $\sigma_{2}=0$ ) and the uniaxial compressive strength $f_{\mathrm{c}}$ is equal to $1 \cdot 5 \cdot f_{\mathrm{c}}^{-0 \cdot 075}$, as per

7. $e=\frac{44 \cdot 55 f_{\mathrm{c}}^{-0.075}+6 \cdot 75 f_{\mathrm{c}}^{-0.15}-3}{89 \cdot 1 f_{\mathrm{c}}^{-0.075}-6 \cdot 75 f_{\mathrm{c}}^{-0.15}+3}$

The value of $e$ given by Equation 7 varies from 0.50 to 0.53 as the compressive strength $f_{\mathrm{c}}$ increases from $20 \mathrm{MPa}$ to higher than $100 \mathrm{MPa}$. For comparison, it is noted that Menétrey and Willam (1995) used a constant value of $e=0 \cdot 52$.

The failure surface so derived is compared with the DruckerPrager failure surface and the extended Drucker-Prager failure surface in Figure 2. Since there is no explicit expression of $f_{\mathrm{cc}}$

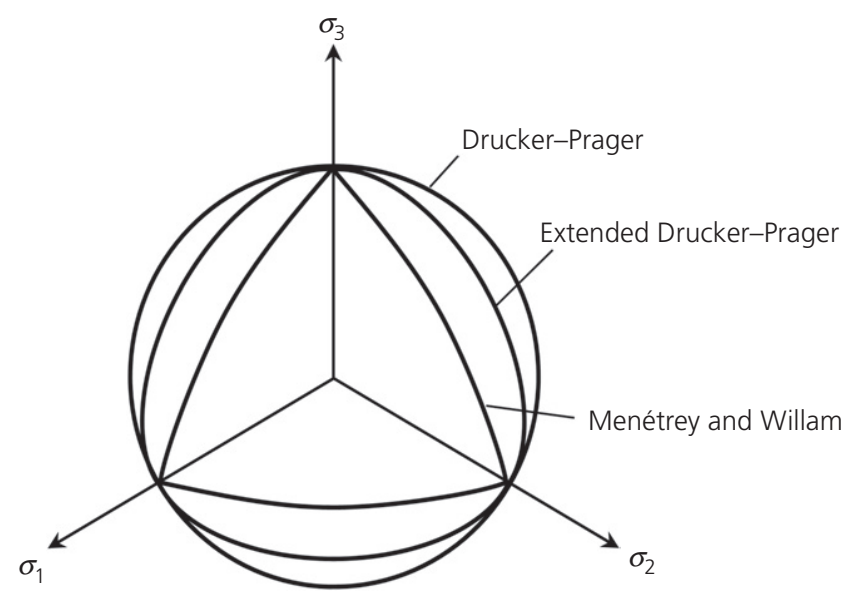

Figure 2. Different failure surfaces in deviatoric plane

\subsection{Axial stress-strain constitutive model}

For modelling the non-linear axial stress-strain behaviour of the confined concrete, the model developed by Attard and Setunge (1996), which covers a wide range of concrete strength from 20 to $130 \mathrm{MPa}$, is used. The axial stress-strain relation of this model is given by

8. $\frac{\sigma_{\mathrm{c}}}{f_{\mathrm{cc}}}=\frac{a_{1}\left(\varepsilon_{\mathrm{c}} / \varepsilon_{\mathrm{cc}}\right)+a_{2}\left(\varepsilon_{\mathrm{c}} / \varepsilon_{\mathrm{cc}}\right)^{2}}{1+a_{3}\left(\varepsilon_{\mathrm{c}} / \varepsilon_{\mathrm{cc}}\right)+a_{4}\left(\varepsilon_{\mathrm{c}} / \varepsilon_{\mathrm{cc}}\right)^{2}}$

where $\sigma_{\mathrm{c}}$ is the axial concrete stress, $\varepsilon_{\mathrm{c}}$ is the axial strain corresponding to $\sigma_{\mathrm{c}}, \varepsilon_{\mathrm{cc}}$ is the axial strain corresponding to $f_{\mathrm{cc}}$ and $a_{1}, a_{2}, a_{3}$ and $a_{4}$ are coefficients governing the shape of the stress-strain curve. In the FE analysis, $\sigma_{\mathrm{c}}$ and $\varepsilon_{\mathrm{c}}$ are equivalent to $\sigma_{3}$ and $\varepsilon_{3}$, respectively.

According to Attard and Setunge (1996), if the two confining stresses $\sigma_{1}$ and $\sigma_{2}$ are the same and equal to $f_{\mathrm{r}}$ (i.e. $\sigma_{1}=\sigma_{2}=f_{\mathrm{r}}$ ), then the value of $\varepsilon_{\mathrm{cc}}$ can be obtained as

9. $\frac{\varepsilon_{\mathrm{cc}}}{\varepsilon_{\mathrm{co}}}=1+\left(17-0.06 f_{\mathrm{c}}\right)\left(\frac{f_{\mathrm{r}}}{f_{\mathrm{c}}}\right)$

in which $\varepsilon_{\mathrm{co}}$ is the axial strain at peak axial stress of the concrete when unconfined as directly measured by uniaxial compression testing. In the case $\varepsilon_{\mathrm{co}}$ has not been measured, the following equation may be used for its estimation (Attard and Setunge, 1996)

10. $\varepsilon_{\mathrm{co}}=\frac{f_{\mathrm{c}}}{E_{\mathrm{c}}} \frac{4 \cdot 26}{\sqrt[4]{f_{\mathrm{c}}}}$

Likewise, $E_{\mathrm{c}}$ should be directly measured by a uniaxial compression test. If $E_{\mathrm{c}}$ has not been measured, the following equation proposed by Carrasquillo et al. (1981) may be used 
for its estimation

$$
\text { 11. } E_{\mathrm{c}}=\left(3320 \sqrt{f_{\mathrm{c}}}+6900\right)\left(\frac{\rho_{\mathrm{c}}}{2320}\right)^{1.5}
$$

where $\rho_{\mathrm{c}}$ is the density of the concrete in $\mathrm{kg} / \mathrm{m}^{3}$. In this paper, $\rho_{\mathrm{c}}$ is taken as $2320 \mathrm{~kg} / \mathrm{m}^{3}$ for normal-weight concrete.

One set of the coefficients $a_{1}, a_{2}, a_{3}$ and $a_{4}$ is used to define the shape of the ascending branch of the stress-strain curve whereas another set of the coefficients is used to define the shape of the descending branch. Each coefficient for either the ascending branch or the descending branch is expressed as a function of the concrete strength $f_{\mathrm{c}}$ and the confining stress $f_{\mathrm{r}}$ so as to allow for their effects on the shape of the stress-strain curve or, more specifically, the ductility of the concrete. Formulas for all these coefficients have been given by Attard and Setunge (1996) and are therefore not repeated here for brevity. As the value of $f_{\mathrm{r}}$ is changing during the analysis of FRP-confined concrete under compression, the shape of Attard and Setunge's (1996) axial stress-strain curve shifts with $f_{\mathrm{r}}$, so that a typical compressive stress-strain relation of FRP-confined concrete is shown in Figure 3.

However, the model of Attard and Setunge (1996) is applicable only when the two confining stresses are equal $\left(\sigma_{1}=\sigma_{2}=f_{\mathrm{r}}\right)$. When the two confining stresses are not equal $\left(\sigma_{1} \neq \sigma_{2}\right)$, it is not clear what confining stress $f_{\mathrm{r}}$ should be used in the stressstrain curve. The best way to overcome this difficulty is to conduct true triaxial tests with unequal confining stresses applied and develop a new constitutive model applicable to the true triaxial case. Before such a true triaxial constitutive model is available, it is suggested to take the confining stress $f_{\mathrm{r}}$ as an equivalent isotropic confining stress equal to the lesser of $\sigma_{1}$ and $\sigma_{2}$ because the smaller of $\sigma_{1}$ and $\sigma_{2}$ would cause earlier cracking of the concrete and thus should have dominating effects. Hence, the confining stress to be used in conjunction with Attard and Setunge's model is taken to be $f_{\mathrm{r}}=\min \left\{\sigma_{1}, \sigma_{2}\right\}$.

Regarding the behaviour of the concrete under tension, it is assumed that, before the axial stress $\sigma_{\mathrm{c}}$ reaches the tensile strength $f_{\mathrm{t}}$, the concrete is perfectly elastic and, upon reaching the tensile strength, the concrete would crack in the axial direction and the axial stress would immediately drop to zero. Then, the concrete would have no tensile strength in the axial direction.

\subsection{Strain gradient model}

Under eccentric loading, there is a strain gradient across the concrete section and the concrete strength would be slightly higher (Chen and Ho, 2015; Ho and Peng, 2013; Hu et al., 2011; Wu and Jiang, 2013). To allow for this effect, the strain gradient model developed by Ho and Peng (2013) is employed. The original equation given in this model is

12a. $\quad \frac{f_{\mathrm{cc}}^{\prime}}{f_{\mathrm{cc}}}= \begin{cases}0.85 & \text { for } \quad 0 \leq \frac{d}{c}<1.3 \\ 0.92\left(\frac{d}{c}\right)-0.35 & \text { for } 1.3 \leq \frac{d}{c}<2.0 \\ 1.5 & \text { for } 2.0 \leq \frac{d}{c}\end{cases}$

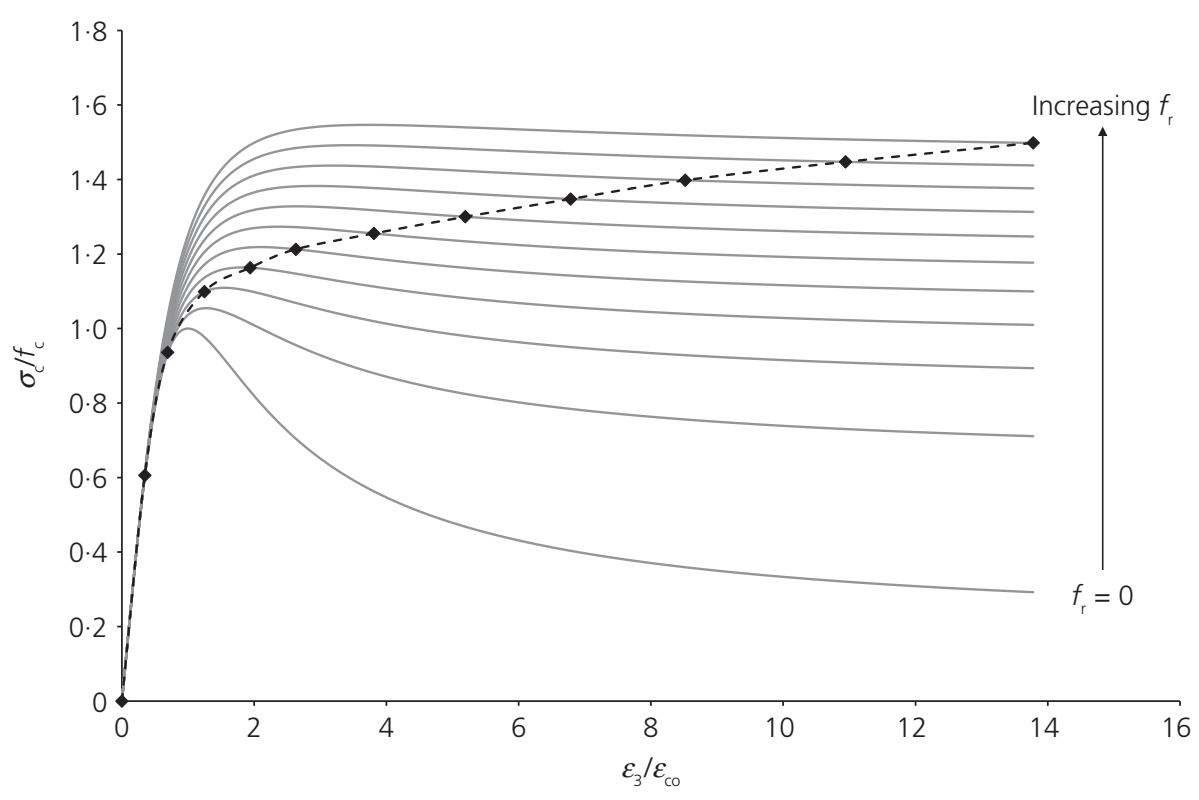

Figure 3. Typical compressive stress-strain relation of FRP-confined concrete 
where $f_{\mathrm{cc}}^{\prime}$ is the increased concrete strength due to the strain gradient effect, $d$ is the effective depth of the concrete section and $c$ is the neutral axis depth. This value of $f_{\mathrm{cc}}^{\prime}$ is used to replace the value of $f_{\text {cc }}$ in Equation 8 when applying Attard and Setunge's model to evaluate the confined concrete strength. Ho and Peng's model takes into account the fact that the axial strength of in situ concrete is approximately equal to $0 \cdot 85 \cdot f_{c}$ due to the differences in size, shape and curing condition. However, if the column specimens have the same size, shape and curing condition as those of the concrete cylinders used to determine $f_{\mathrm{c}}$, there is no need to incorporate the factor 0.85 and Equation 12a should be modified as

$12 b$.

$$
\frac{f_{\mathrm{cc}}^{\prime}}{f_{\mathrm{cc}}}= \begin{cases}1.0 & \text { for } \quad 0 \leq \frac{d}{c}<1.3 \\ 1.08\left(\frac{d}{c}\right)-0.41 & \text { for } \quad 1.3 \leq \frac{d}{c}<2.0 \\ 1.76 & \text { for } \quad 2.0 \leq \frac{d}{c}\end{cases}
$$

\section{FE analysis}

\subsection{Concrete elements}

The concrete section is modelled by $2 \mathrm{D}$ plane strain linear three-node T3 elements. In the formulation, two coordinate systems are used: the global $x-y$ coordinate system and the local 1-2 coordinate system. The local axes 1 and 2 are taken as the principal directions or crack directions after the formation of splitting cracks. Following the standard formulation, the strain vector $\left\{\begin{array}{lll}\varepsilon_{x} & \varepsilon_{y} & \gamma_{x y}\end{array}\right\}^{\mathrm{T}}$ in the global coordinate system (denoted by $\varepsilon^{\prime}$ ) is expressed as a function of the nodal displacement vector (denoted by $\boldsymbol{u}$ ) by the equation $\boldsymbol{\varepsilon}^{\prime}=\mathbf{B} \boldsymbol{u}$, in which $\mathbf{B}$ is the strain-displacement matrix. The strain vector $\boldsymbol{\varepsilon}^{\prime}$ in the global coordinate system is then transformed to the strain vector $\left\{\begin{array}{lll}\varepsilon_{1} & \varepsilon_{2} & \gamma_{12}\end{array}\right\}^{\mathrm{T}}$ in the local coordinate system (denoted by $\boldsymbol{\varepsilon}$ ) by the equation $\boldsymbol{\varepsilon}=\mathbf{A} \boldsymbol{\varepsilon}^{\prime}$, in which $\mathbf{A}$ is the strain transformation matrix.

In the local coordinate system, the stress-strain relation is given by Equation 4. Expressed in matrix form we have

$$
\text { 13. } \boldsymbol{\sigma}=\mathbf{C}\left(\boldsymbol{\varepsilon}-\boldsymbol{\varepsilon}_{1,2}^{\mathrm{p}}\right)+\lambda v_{\mathrm{c}} \boldsymbol{\varepsilon}_{3}
$$

where $\sigma$ is the stress vector $\left\{\sigma_{1} \sigma_{2} \tau_{12}\right\}^{\mathrm{T}}$ in the local coordinate system, $\sigma \varepsilon_{1,2}^{\mathrm{p}}$ is the residual strain vector $\left\{\varepsilon_{1}^{\mathrm{p}} \varepsilon_{2}^{\mathrm{p}} 0\right\}^{\mathrm{T}}, \varepsilon_{3}$ is the axial strain vector $\left\{\begin{array}{lll}\varepsilon_{3} & \varepsilon_{3} & 0\end{array}\right\}^{\mathrm{T}}$ and $\mathbf{C}$ is the constitutive matrix, given by

$$
\text { 14. } \mathbf{C}=\lambda\left[\begin{array}{ccc}
1-v_{\mathrm{c}} & v_{\mathrm{c}} & 0 \\
v_{\mathrm{c}} & 1-v_{\mathrm{c}} & 0 \\
0 & 0 & \left(1-v_{\mathrm{c}}\right) / 2
\end{array}\right]
$$

From the stress vector $\sigma$ in the local coordinate system, the stress vector $\left\{\begin{array}{llll}\sigma_{x} & \sigma_{y} & \tau_{x y}\end{array}\right\}^{\mathrm{T}}$ in the global coordinate system (denoted by $\boldsymbol{\sigma}^{\prime}$ ) is obtained as $\boldsymbol{\sigma}^{\prime}=\mathbf{A}^{\mathrm{T}} \boldsymbol{\sigma}$, and the nodal force vector $\boldsymbol{F}$ in the global coordinate system is obtained as $\boldsymbol{F}=\mathbf{B}^{\mathrm{T}} \boldsymbol{\sigma}^{\prime}$. After such transformations, the element stiffness matrix equation in the global $x-y$ coordinate system is obtained as

$$
\text { 15. } \quad \boldsymbol{F}=\Delta\left\{\mathbf{B}^{\mathrm{T}} \mathbf{A}^{\mathrm{T}} \mathbf{C} \mathbf{A} \mathbf{B} \boldsymbol{u}-\mathbf{B}^{\mathrm{T}} \mathbf{A}^{\mathrm{T}} \mathbf{C} \boldsymbol{\varepsilon}_{1,2}^{\mathrm{p}}+\mathbf{B}^{\mathrm{T}}\left(\lambda v_{\mathrm{c}} \boldsymbol{\varepsilon}_{3}\right)\right\}
$$

in which $\Delta$ is the area of the T3 element. In the above equation, the terms $\varepsilon_{1,2}^{\mathrm{p}}$ can be regarded as the residual strain.

For each concrete element, the axial strain $\varepsilon_{3}$ is taken as that at the centroid of the element. Furthermore, before the axial strain reaches the splitting crack limit $\varepsilon_{3,1}^{\mathrm{o}}$ or $\varepsilon_{3,2}^{\mathrm{o}}$, the local 1 and 2 directions are taken as the principal strain directions and, once the axial strain reaches either $\varepsilon_{3,1}^{o}$ or $\varepsilon_{3,2}^{o}$, the concrete element is deemed to have splitting cracks formed and the local 1 and 2 directions are set along and perpendicular to the crack so that the angle between the $1-2$ axes and the $x-y$ axes is fixed.

\subsection{FRP elements}

The FRP wrap is modelled by two-node bar elements. Since FRP is perfectly elastic before rupture, constant stiffness is assumed. The standard formulation is followed to derive the element stiffness matrix equation as

16. $\left\{\begin{array}{l}Q_{1} \\ R_{1} \\ Q_{2} \\ R_{2}\end{array}\right\}=\frac{t_{\mathrm{f}} E_{\mathrm{f}}}{L_{\mathrm{f}}}\left[\begin{array}{cccc}c^{2} & c s & -c^{2} & -c s \\ c s & s^{2} & -c s & -s^{2} \\ -c^{2} & -c s & c^{2} & c s \\ -c s & -s^{2} & c s & s^{2}\end{array}\right]\left\{\begin{array}{c}u_{1} \\ v_{1} \\ u_{2} \\ v_{2}\end{array}\right\}$

where $t_{\mathrm{f}}$ is the thickness of the FRP, $E_{\mathrm{f}}$ is Young's modulus of the FRP, $L_{\mathrm{f}}$ is the length of the bar element, $c$ and $s$ stand for $\cos \theta_{\mathrm{f}}$ and $\sin \theta_{\mathrm{f}}$ respectively, $\theta_{\mathrm{f}}$ is the orientation angle of the bar element in the global $x-y$ coordinate system, $\left\{\begin{array}{llll}u_{1} & v_{1} & u_{2} & v_{2}\end{array}\right\}^{\mathrm{T}}$ is the nodal displacement vector and $\left\{\begin{array}{lllll}Q_{1} & R_{1} & Q_{2} & R_{2}\end{array}\right\}^{\mathrm{T}}$ is the nodal force vector.

\subsection{Method of analysis}

Although the confined concrete column is subjected to triaxial stresses, the concrete column is analysed using section analysis (Ho et al., 2003, 2010; Kwan and Liauw, 1985) with the biaxial confining stresses evaluated by 2D FE analysis. To generate the axial load-axial strain curve of the column, the column is loaded by prescribed axial strain at the loading point starting from zero and increasing in small increments until the FRP ruptures or the axial load on the column has reached a peak value and then dropped by more than $30 \%$.

For the section analysis, the assumption 'plane sections remain plane after loading' is made (Ho et al., 2003, 2010; Kwan and Liauw, 1985). Under eccentric loading, the section would be 
subjected to axial load and biaxial bending, and the axial deformation can be fully described by an overall axial strain and two biaxial curvatures. Let the eccentric load be applied at the point $\left(x_{\mathrm{p}}, y_{\mathrm{p}}\right)$, the axial strain at the loading point be $\varepsilon_{\mathrm{p}}$, and the biaxial curvatures about the $x$-axis and $y$-axis be $\omega_{x}$ and $\omega_{y}$, respectively, as shown in Figure 4. Since the section moves as a plane, the axial strain $\varepsilon_{3}$ at each point $(x, y)$ in the section is given by

\section{7. $\varepsilon_{3}=\varepsilon_{\mathrm{p}}+\omega_{y}\left(x-x_{\mathrm{p}}\right)+\omega_{x}\left(y-y_{\mathrm{p}}\right)$}

From the axial strain $\varepsilon_{3}$, the axial stress $\sigma_{3}$ can be evaluated using the model of Attard and Setunge (1996) model. However, this requires knowledge of the biaxial confining stresses $\sigma_{1}$ and $\sigma_{2}$, which are to be determined by the 2D FE analysis. The standard procedures of $2 \mathrm{D}$ plane strain analysis are followed. First, the element stiffness matrix equations of the concrete and FRP elements (i.e. Equations 15 and 16) are assembled to form the global stiffness matrix equation. In the in-plane directions, there are actually no external loads. Hence, no external loads need to be applied. Only the residual strains due to the inelastic lateral strains $\varepsilon_{1}^{\mathrm{p}}$ and $\varepsilon_{2}^{\mathrm{p}}$ and the residual stresses due to the axial strain $\varepsilon_{3}$ are causing internal stresses. In the end, the global stiffness matrix equation is given by

\section{8. $\boldsymbol{K} \cdot \boldsymbol{u}=\boldsymbol{F}_{\mathrm{p}}\left\{\boldsymbol{\varepsilon}_{1,2}^{\mathrm{p}}\left[\boldsymbol{\sigma}(\boldsymbol{u}), \varepsilon_{3}\right]\right\}-\boldsymbol{F}_{3}\left(\boldsymbol{\varepsilon}_{3}\right)$}

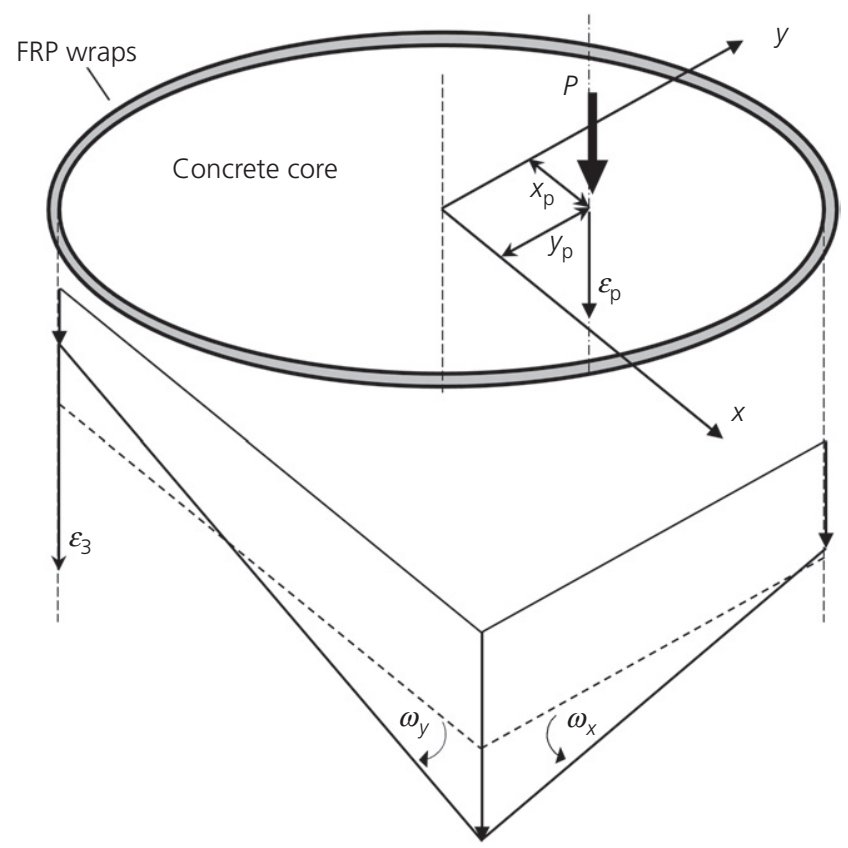

Figure 4. FRP-confined concrete column section under eccentric loading where $\boldsymbol{F}_{\mathrm{p}}$ and $\boldsymbol{F}_{3}$ are load vectors related to inelastic lateral strains and axial strain in concrete, respectively. To find the values of lateral strains and confining stresses in each concrete element, nodal displacements have to be determined from Equation 18. However, since the right-hand side of Equation 18 is also dependent on nodal displacements, it is obvious that Equation 18 is a non-linear matrix system, which requires specific numerical techniques, such as an iteration process for approximate solutions with Equation 18 being solved repeatedly. For example, a nodal displacement vector $\boldsymbol{u}_{i}$ can be calculated using the current values of axial strain and confining stresses in step $i$

19. $\boldsymbol{K} \cdot \boldsymbol{u}_{i}=\boldsymbol{F}_{\mathrm{p}}\left\{\boldsymbol{\varepsilon}_{1,2}^{\mathrm{p}}\left[\boldsymbol{\sigma}_{i}, \boldsymbol{\varepsilon}_{3}\right]\right\}-\boldsymbol{F}_{3}\left(\boldsymbol{\varepsilon}_{3}\right)$

The global stiffness matrix equation is solved for $\boldsymbol{u}_{i}$ using lower, diagonal and upper matrices (LDU) decomposition (or Cholesky decomposition) and band-solver. Then the new nodal displacement vector can be used to produce a new stress vector $\boldsymbol{\sigma}_{i}^{\prime}$, which is used to compute the confining stresses for step $i+1$

20. $\boldsymbol{\sigma}_{i+1}=r \cdot \boldsymbol{\sigma}_{i}+(1-r) \cdot \boldsymbol{\sigma}_{i}^{\prime}\left(\boldsymbol{u}_{i}\right) \quad(0<r<1)$

where $r$ is the relaxation factor. Normally the value of $r$ is set between 0.3 and 0.7 to maintain the convergence rate during the iteration process.

In general, the iterative procedure for calculating the lateral strains and confining stresses can be summarised as follows. First, the axial strains as given by Equation 17 are applied to the concrete elements. Second, using the confining stresses evaluated in the previous iteration, the inelastic lateral strains are evaluated as per Equations $3 \mathrm{a}$ and $3 \mathrm{~b}$. Third, based on the inelastic lateral strains so evaluated, the $2 \mathrm{D} \mathrm{FE}$ analysis is performed to obtain a new set of confining stresses. The whole procedure is repeated until the inelastic lateral strains and confining stresses converge to steady values.

Having determined the biaxial confining stresses and evaluated the axial stress at each concrete element, the axial load $P$ acting on the concrete section can be calculated by integrating $\sigma_{3}$ over the whole concrete section and the internal moments $M_{x}$ and $M_{y}$ about the $x$-axis and $y$-axis can be calculated by integrating $\sigma_{3} y$ and $\sigma_{3} x$, respectively, over the whole concrete section. To satisfy the equilibrium between the external moments $\left(P \cdot y_{\mathrm{p}}\right.$ and $\left.P \cdot x_{\mathrm{p}}\right)$ and the internal moments $\left(M_{x}\right.$ and $M_{y}$ ), the biaxial curvatures $\omega_{x}$ and $\omega_{y}$ have to be adjusted such that $P \cdot y_{\mathrm{p}}+M_{x}=0$ and $P \cdot x_{\mathrm{p}}+M_{y}=0$. This is done iteratively by applying small changes to $\omega_{x}$ and $\omega_{y}$, repeating the whole process of evaluating the axial strain $\varepsilon_{3}$, determining the biaxial confining stresses $\sigma_{1}$ and $\sigma_{2}$, evaluating the axial stress $\sigma_{3}$ and integrating to obtained new values of $P, M_{x}$ and $M_{y}$ until the moment equilibrium condition is satisfied. The values 
of the biaxial curvatures $\omega_{x}$ and $\omega_{y}$ for each iteration can be determined through the secant method (Liang and Fragomeni, 2010)

21a. $\omega_{x, i+2}=\omega_{x, i+1}-\frac{\left(\omega_{x, i+1}-\omega_{x, i}\right) \cdot \mathrm{RE}_{x, i+1}}{\mathrm{RE}_{x, i+1}-\mathrm{RE}_{x, i}}$

$21 b$

$$
\omega_{y, i+2}=\omega_{y, i+1}-\frac{\left(\omega_{y, i+1}-\omega_{y, i}\right) \cdot \mathrm{RE}_{y, i+1}}{\mathrm{RE}_{y, i+1}-\mathrm{RE}_{y, i}}
$$

where RE stands for the remainders between the external moments and the internal moments given by $\mathrm{RE}_{x}=P \cdot y_{\mathrm{p}}+M_{x}$ and $\mathrm{RE}_{y}=P \cdot x_{\mathrm{p}}+M_{y}$ if they do not meet the equilibrium condition. The iteration process will stop until the absolute values of the remainders are smaller than the allowance limit (normally very small). It should be noted that the value of $f_{\mathrm{cc}}$ on the triaxial failure surface can be determined similarly by this secant method.

On the whole, there are three iteration loops, which are depicted schematically in Figure 5. The first iteration loop

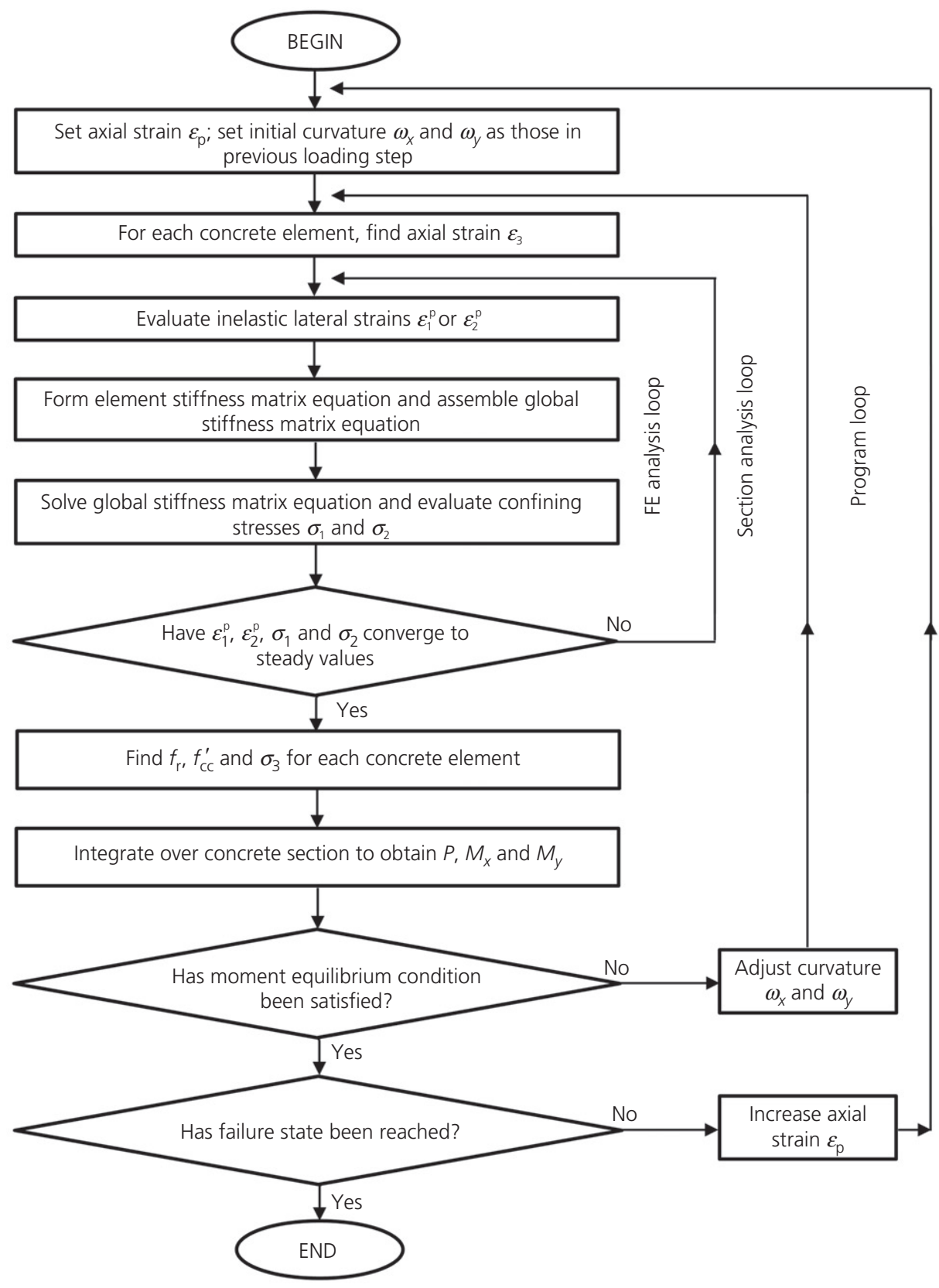

Figure 5. Procedures for the proposed FE analysis 
comprises loading steps in which loading is applied incrementally at the loading point in the form of a prescribed axial strain $\varepsilon_{\mathrm{p}}$. The second iteration loop is that, at each loading step, the biaxial curvatures $\omega_{x}$ and $\omega_{y}$ are adjusted until the bending moments evaluated satisfy the moment equilibrium condition. The third iteration loop is that, for each given set of axial strain $\varepsilon_{\mathrm{p}}$ and biaxial curvatures $\omega_{x}$ and $\omega_{y}$, the axial strain $\varepsilon_{3}$ at each point in the section is evaluated and successive 2D FE analysis using updated inelastic lateral strains is performed until steady values of inelastic lateral strains and confining stresses are obtained. From the confining stresses so obtained, the axial stress $\sigma_{3}$ in each element is evaluated and the axial load and bending moments acting on the section are obtained by integration.

\section{FE analysis of FRP-confined concrete columns}

\subsection{Eccentric load-displacement relation}

The proposed FE method was verified against the FRP-confined circular concrete columns reported by $\mathrm{Wu}$ and Jiang (2013), which have no internal steel reinforcements, under eccentric loading. The concrete columns tested were all of $150 \mathrm{~mm}$ diameter and $300 \mathrm{~mm}$ length, which were the same as the dimensions of the concrete cylinders used to determine $f_{\mathrm{c}}$. The FRP wraps, made of unidirectional carbon fibre, were all applied horizontally to the concrete columns. They had a Young's modulus of $254.0 \mathrm{GPa}$ and a thickness of either $0.167 \mathrm{~mm}$ (one-ply) or $0.334 \mathrm{~mm}$ (two-ply). Two concrete mixes were used to cast the columns; they had unconfined cylinder strengths of $28.7 \mathrm{MPa}$ and $30.1 \mathrm{MPa}$ and Young's moduli of $42.9 \mathrm{GPa}$ and $42.1 \mathrm{GPa}$, respectively. The eccentricity $\left(d_{\mathrm{e}}\right)$ of the applied load ranged from $0 \mathrm{~mm}$ to $50 \mathrm{~mm}$ in $10 \mathrm{~mm}$ intervals. It should be noted that the moment equilibrium condition becomes $P \cdot d_{\mathrm{e}}+M_{y}=0$ for this specific configuration, so that only uniaxial curvature about the $y$-axis needs to be determined in the FE analysis. For each configuration, two specimens were tested; except for the E50 group only the test results of one specimen were reported because the linear variable differential transformer of one of the specimens failed to function properly. The section properties and test results of the specimens are listed in Table 1: $P_{\text {test }}$ is the maximum load obtained from the test and $\delta_{\mathrm{a}, \mathrm{f}}$ is the corresponding axial displacement at the loading point.

In the first place, the FE mesh has to be generated. In the case that the concrete column section to be analysed is symmetric,

\begin{tabular}{|c|c|c|c|c|c|c|c|c|c|c|c|}
\hline Test ID & $f_{\mathrm{c}}: \mathrm{MPa}$ & $E_{\mathrm{c}}: \mathrm{GPa}$ & $t_{\mathrm{f}}: \mathrm{mm}$ & $d_{\mathrm{e}}: m m$ & $\delta_{\mathrm{a}, \mathrm{f}}: \mathrm{mm}$ & $P_{\text {test }}: \mathrm{kN}$ & $P_{\mathrm{FE}-1}: \mathrm{kN}$ & $\frac{P_{\mathrm{FE}-\mathrm{I}}}{P_{\text {test }}}$ & $P_{\mathrm{FE}-11}: \mathrm{kN}$ & $\frac{P_{\mathrm{FE}-\|}}{P_{\text {test }}}$ & PD: \% \\
\hline A1E0 & $28 \cdot 7$ & $42 \cdot 9$ & $0 \cdot 167$ & 0 & 5.09 & $1048 \cdot 6$ & $923 \cdot 7$ & 0.88 & $929 \cdot 3$ & 0.89 & -0.53 \\
\hline B1E0 & $28 \cdot 7$ & $42 \cdot 9$ & $0 \cdot 167$ & 0 & $4 \cdot 31$ & $968 \cdot 7$ & $863 \cdot 7$ & 0.89 & $868 \cdot 2$ & 0.90 & -0.46 \\
\hline A1E10 & $28 \cdot 7$ & $42 \cdot 9$ & $0 \cdot 167$ & 10 & 3.98 & $938 \cdot 7$ & $806 \cdot 2$ & 0.86 & $802 \cdot 3$ & 0.85 & 0.42 \\
\hline B1E10 & $28 \cdot 7$ & $42 \cdot 9$ & $0 \cdot 167$ & 10 & $3 \cdot 89$ & $880 \cdot 7$ & 798.6 & 0.91 & $794 \cdot 0$ & 0.90 & 0.52 \\
\hline A1E20 & $28 \cdot 7$ & $42 \cdot 9$ & $0 \cdot 167$ & 20 & $4 \cdot 36$ & $850 \cdot 7$ & 734.5 & 0.86 & $731 \cdot 7$ & 0.86 & 0.33 \\
\hline B1E20 & $28 \cdot 7$ & $42 \cdot 9$ & $0 \cdot 167$ & 20 & $3 \cdot 21$ & $739 \cdot 7$ & $657 \cdot 2$ & 0.89 & $654 \cdot 8$ & 0.89 & $0 \cdot 32$ \\
\hline A1E30 & $28 \cdot 7$ & $42 \cdot 9$ & $0 \cdot 167$ & 30 & $4 \cdot 23$ & $755 \cdot 7$ & $673 \cdot 1$ & 0.89 & $650 \cdot 8$ & 0.86 & $2 \cdot 95$ \\
\hline B1E30 & $28 \cdot 7$ & $42 \cdot 9$ & $0 \cdot 167$ & 30 & 4.06 & $768 \cdot 7$ & $665 \cdot 2$ & 0.87 & $642 \cdot 8$ & 0.84 & $2 \cdot 91$ \\
\hline A1E40 & $28 \cdot 7$ & $42 \cdot 9$ & $0 \cdot 167$ & 40 & $4 \cdot 33$ & $691 \cdot 7$ & $690 \cdot 4$ & 1.00 & $683 \cdot 3$ & 0.99 & 1.03 \\
\hline B1E40 & $28 \cdot 7$ & $42 \cdot 9$ & $0 \cdot 167$ & 40 & $3 \cdot 76$ & $633 \cdot 8$ & $658 \cdot 3$ & 1.04 & $648 \cdot 8$ & 1.02 & $1 \cdot 50$ \\
\hline B1E50 & $28 \cdot 7$ & $42 \cdot 9$ & $0 \cdot 167$ & 50 & $3 \cdot 37$ & $434 \cdot 8$ & $443 \cdot 5$ & 1.02 & $428 \cdot 0$ & 0.98 & $3 \cdot 56$ \\
\hline A2E0 & $30 \cdot 1$ & $42 \cdot 1$ & $0 \cdot 334$ & 0 & $7 \cdot 78$ & $1557 \cdot 5$ & $1450 \cdot 5$ & 0.93 & $1458 \cdot 1$ & 0.94 & -0.49 \\
\hline B2E0 & $30 \cdot 1$ & $42 \cdot 1$ & $0 \cdot 334$ & 0 & $7 \cdot 61$ & $1597 \cdot 5$ & $1436 \cdot 6$ & 0.90 & $1443 \cdot 2$ & 0.90 & -0.41 \\
\hline A2E10 & $30 \cdot 1$ & $42 \cdot 1$ & $0 \cdot 334$ & 10 & $7 \cdot 17$ & $1463 \cdot 5$ & $1278 \cdot 2$ & 0.87 & $1267 \cdot 1$ & 0.87 & 0.76 \\
\hline B2E10 & $30 \cdot 1$ & $42 \cdot 1$ & $0 \cdot 334$ & 10 & $7 \cdot 10$ & $1434 \cdot 5$ & $1272 \cdot 7$ & 0.89 & $1261 \cdot 5$ & 0.88 & 0.78 \\
\hline A2E20 & $30 \cdot 1$ & $42 \cdot 1$ & $0 \cdot 334$ & 20 & 6.03 & $1267 \cdot 6$ & $1020 \cdot 0$ & 0.80 & $1009 \cdot 8$ & 0.80 & 0.80 \\
\hline B2E20 & $30 \cdot 1$ & $42 \cdot 1$ & $0 \cdot 334$ & 20 & $6 \cdot 69$ & $1349 \cdot 5$ & $1066 \cdot 6$ & 0.79 & $1055 \cdot 1$ & 0.78 & 0.85 \\
\hline A2E30 & $30 \cdot 1$ & $42 \cdot 1$ & $0 \cdot 334$ & 30 & $6 \cdot 30$ & $1164 \cdot 6$ & $943 \cdot 1$ & 0.81 & $929 \cdot 7$ & $0 \cdot 80$ & $1 \cdot 15$ \\
\hline B2E30 & $30 \cdot 1$ & $42 \cdot 1$ & $0 \cdot 334$ & 30 & $6 \cdot 48$ & $1201 \cdot 6$ & $952 \cdot 8$ & 0.79 & $941 \cdot 9$ & 0.78 & 0.91 \\
\hline A2E40 & $30 \cdot 1$ & $42 \cdot 1$ & $0 \cdot 334$ & 40 & $5 \cdot 48$ & $908 \cdot 7$ & $883 \cdot 2$ & 0.97 & $840 \cdot 5$ & 0.92 & $4 \cdot 70$ \\
\hline B2E40 & $30 \cdot 1$ & $42 \cdot 1$ & $0 \cdot 334$ & 40 & 4.04 & $766 \cdot 1$ & 779.6 & 1.02 & $740 \cdot 7$ & 0.97 & 5.08 \\
\hline B2E50 & $30 \cdot 1$ & $42 \cdot 1$ & $0 \cdot 334$ & 50 & $3 \cdot 46$ & $560 \cdot 6$ & $479 \cdot 7$ & 0.86 & $442 \cdot 4$ & 0.79 & $6 \cdot 65$ \\
\hline Mean & & & & & & & & 0.90 & & 0.88 & \\
\hline \multicolumn{8}{|c|}{ Coefficient of variance (= standard deviation/mean) } & $7 \cdot 1 \%$ & & $7 \cdot 7 \%$ & \\
\hline
\end{tabular}

Table 1. Experimental and FE analysis results for specimens studied by Wu and Jiang (2013) 
only half of the section is meshed for FE analysis so as to simplify the FE model. A 2D mesh of a FRP-confined circular concrete column section is shown in Figure 6 as an example. The larger the eccentricity, the greater the gradient of stress fields over the cross-section will be. To achieve simulation results with good confidence for sections under eccentric loading, the domain of each T3 element in the concerned area therefore has to be fairly small to approximate the stress fields with drastic variation, resulting in a fine T3 mesh. In order to determine the influence of mesh density on the numerical results, 2203-element, 4483-element, 5923-element and 6718element meshes were respectively tested in the FE analyses of B2E50 where the largest variations of stresses were expected to occur over the cross-section among the specimens by $\mathrm{Wu}$ and

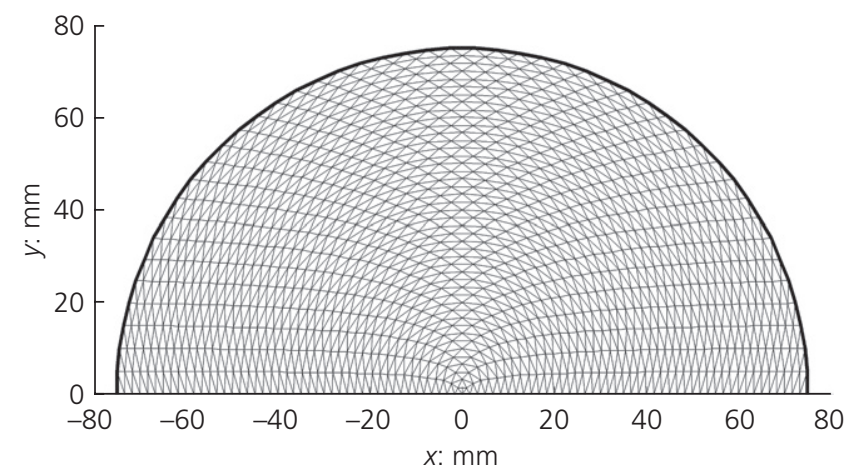

Figure 6. 2D mesh of a FRP-confined circular concrete column section
Jiang (2013). Using a computer with a dual-core $3 \cdot 33 \mathrm{GHz}$ Intel CPU and 3.25 GB RAM running in a Windows 7 32-bit environment, the simulation process of one specimen took 15-45 min depending on the number of elements (2203 to 6718). The predicted maximum loads by the FE analysis $\left(P_{\mathrm{FE}}\right)$ for each mesh density were normalised by the experimental result and the numerical result of the 6718-element mesh, as shown in Figure 7. It can be observed that the numerical result steadily converged when the number of mesh elements was around 6000 . When normalised by the experimental result, the difference between the 2203-element mesh and the 6718element mesh, which was the largest for any two meshes considered, was $6.7 \%$. To further study the relations between mesh density and other parameters, both the 2203-element mesh and the 6718-element mesh were adopted in the FE analysis. The numerical results for the specimens studied by $\mathrm{Wu}$ and Jiang (2013) are listed in Table 1, where $P_{\text {FE-I }}$ and $P_{\text {FE-II }}$ respectively correspond to the 2203-element mesh and the 6718-element mesh.

The load-displacement curves as obtained by the FE analysis are compared with those obtained experimentally in Figure 8 (one-ply group) and Figure 9 (two-ply group), where FE-I and FE-II indicate FE analysis results obtained by the 2203-elment mesh and the 6718-element mesh, respectively. From Figure 8(a) and Figure 9(a), it can be seen that for specimens A1E0 and B1E0 $\left(d_{\mathrm{e}}=0 \mathrm{~mm}\right.$, one-ply), the FE analysis slightly underestimates the loading by about $10 \%$ during the whole inelastic stage, whereas for specimens A2E0 and B2E0 ( $d_{\mathrm{e}}=0 \mathrm{~mm}$, two-ply), the FE analysis yields predicted loading in close agreement with the experimental results at small

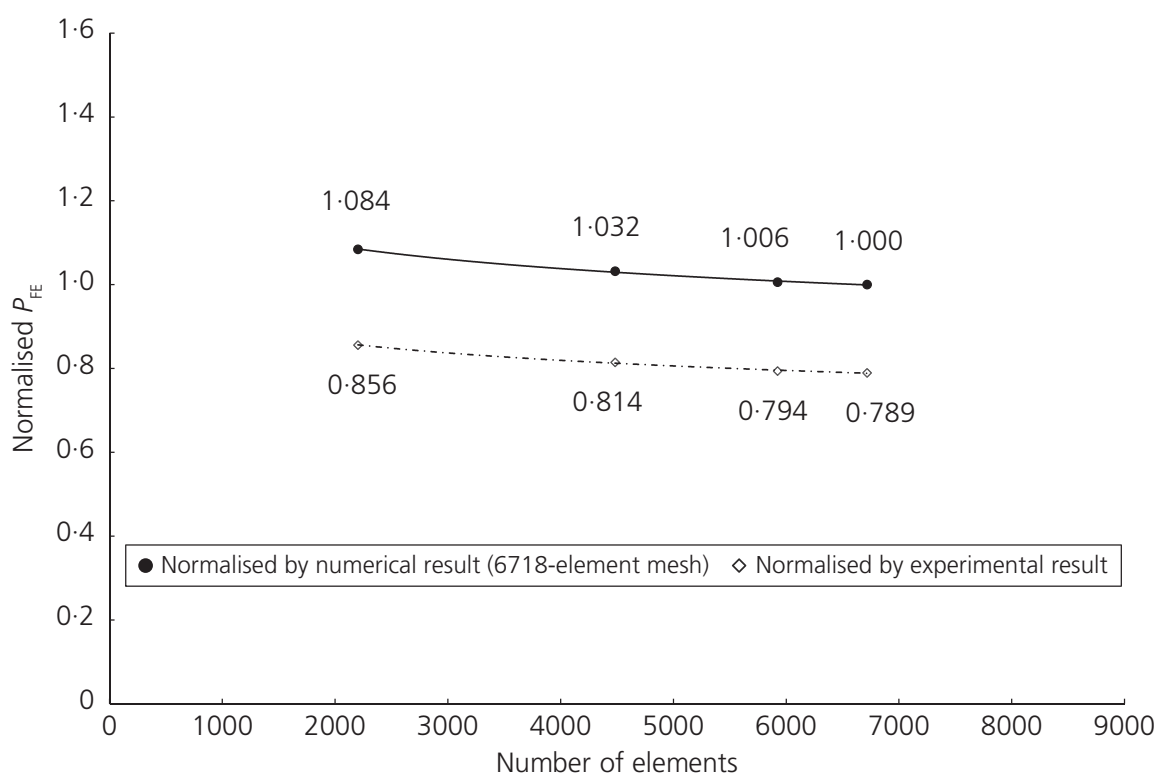

Figure 7. FE analysis of $\mathrm{A} 1 \mathrm{E} 10$ and $\mathrm{B} 1 \mathrm{E} 10$ using two different meshes 


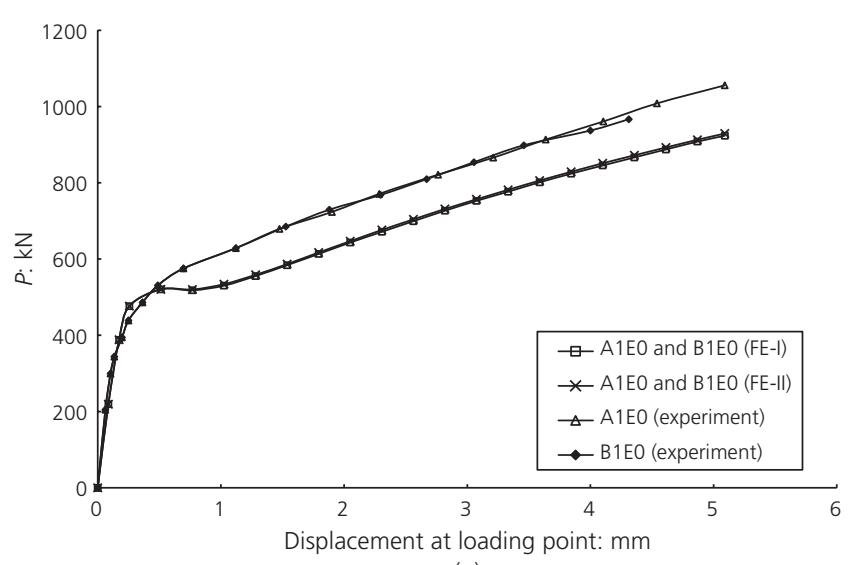

(a)

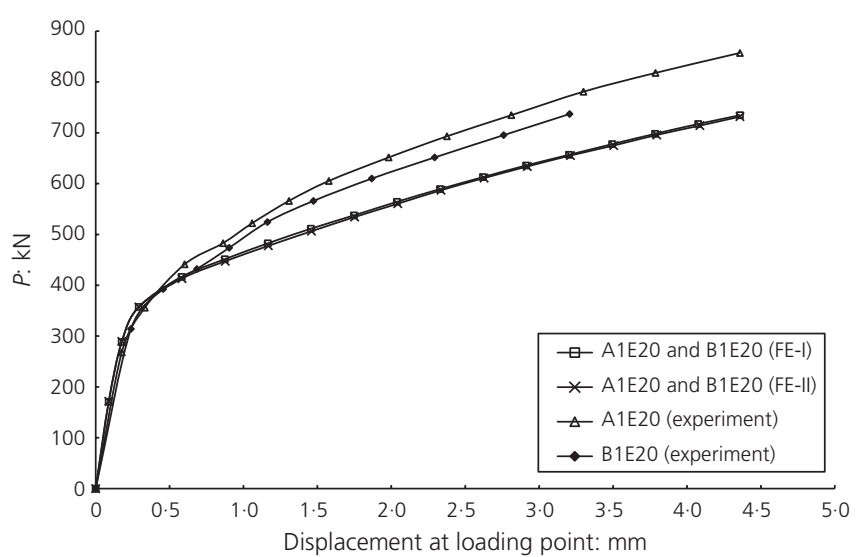

(c)

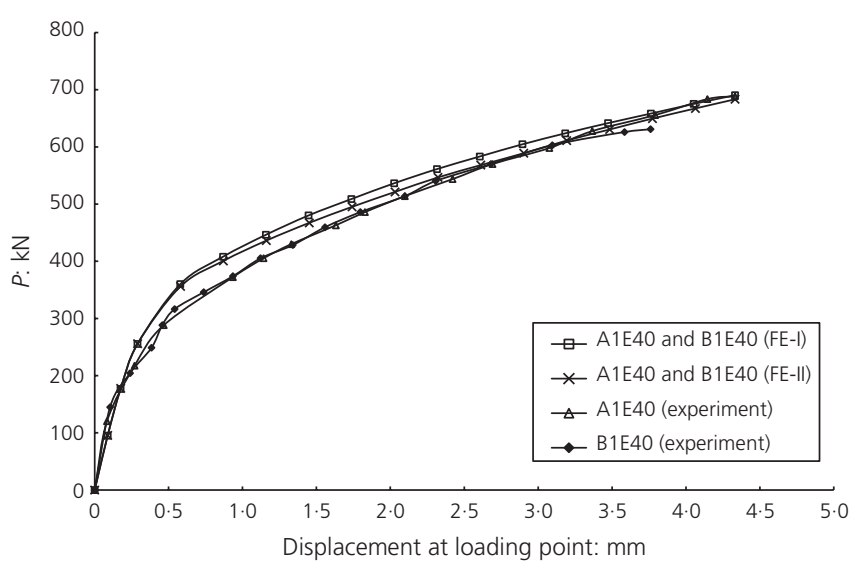

(e)

Figure 8. Load-displacement curves for specimens with one-ply FRP: (a) A1E0 and B1E0; (b) A1E10 and B1E10; (c) A1E20 and B1E20; (d) A1E30 and B1E30; (e) A1E40 and B1E40; (f) B1E50

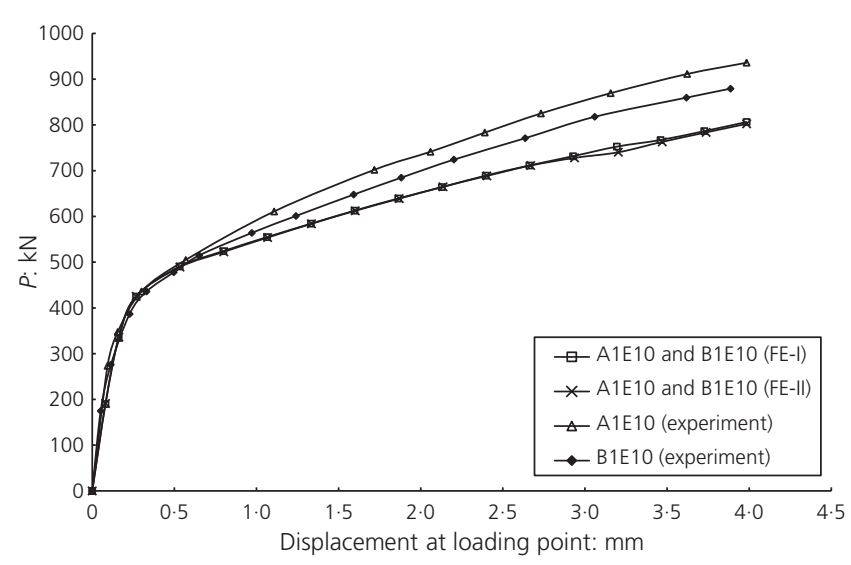

(b)

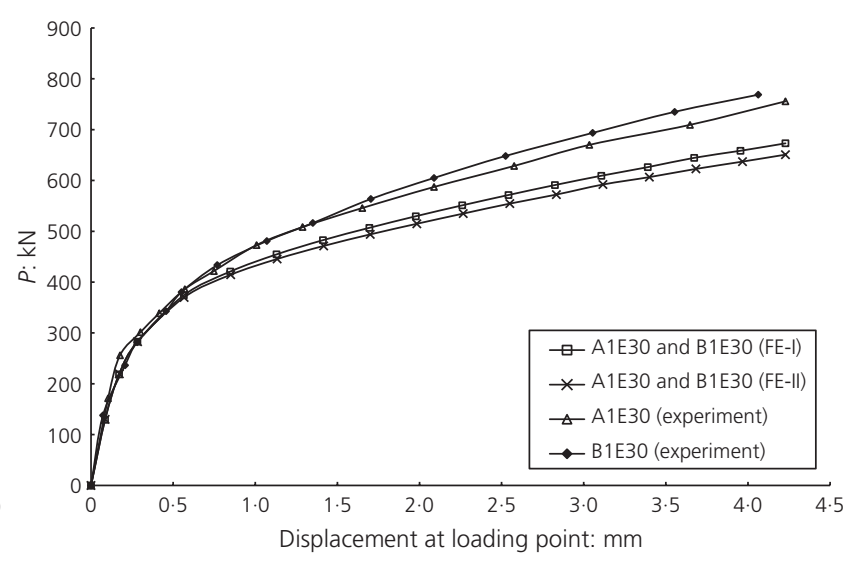

(d) displacements (less than $6 \mathrm{~mm}$ ) but still slightly underestimates the loading by about $10 \%$ at large displacements (greater than $6 \mathrm{~mm})$.

From Figures 8(b)-8(d), it is noted that for specimens A1E10 and B1E10 ( $d_{\mathrm{e}}=10 \mathrm{~mm}$, one-ply), A1E20 and B1E20 $\left(d_{\mathrm{e}}=20 \mathrm{~mm}\right.$, one-ply) and A1E30 and B1E30 $\left(d_{\mathrm{e}}=30 \mathrm{~mm}\right.$, one-ply), the FE analysis slightly underestimates the loading by about $5-15 \%$ during the inelastic stage. On the other hand, from Figures 9(b)-9(d), it is noted that for specimens A2E10 and B2E10 $\left(d_{\mathrm{e}}=10 \mathrm{~mm}\right.$, two-ply), A2E20 and B2E20 $\left(d_{\mathrm{e}}=20 \mathrm{~mm}\right.$, two-ply $)$ and $\mathrm{A} 2 \mathrm{E} 30$ and $\mathrm{B} 2 \mathrm{E} 30\left(d_{\mathrm{e}}=30 \mathrm{~mm}\right.$, 


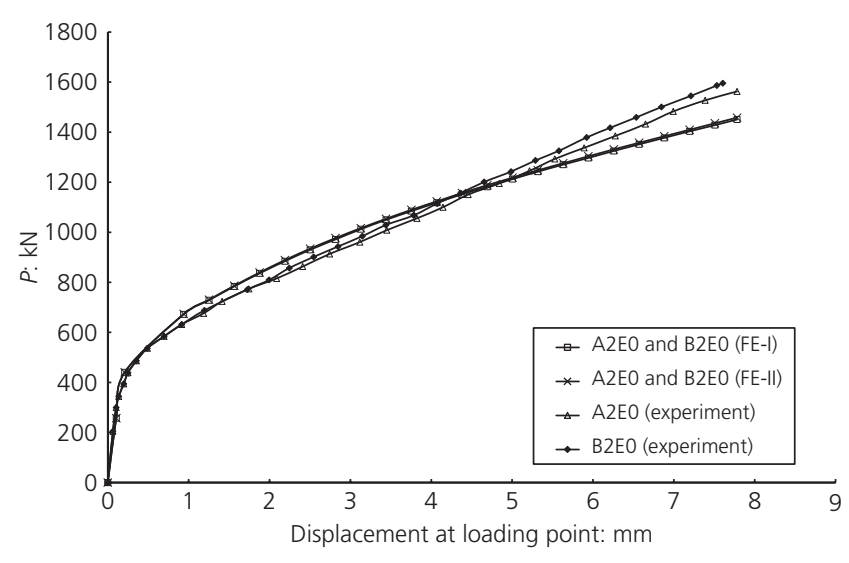

(a)

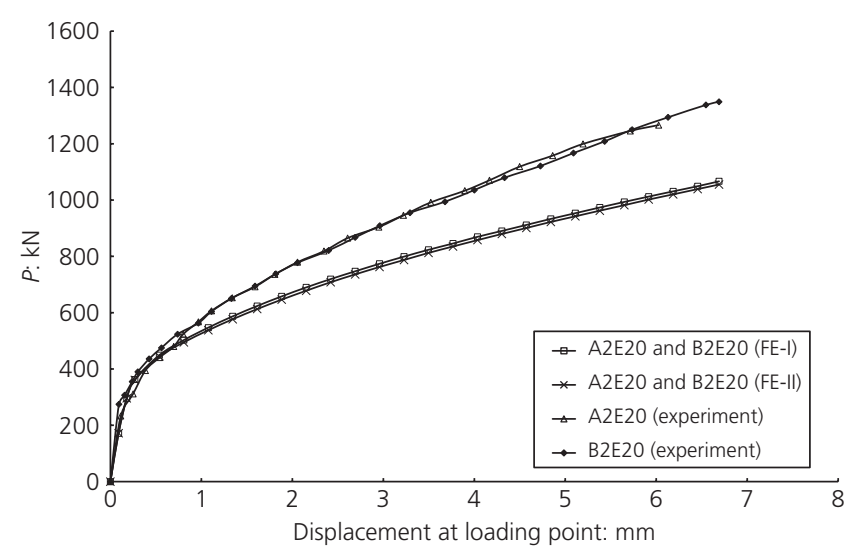

(c)

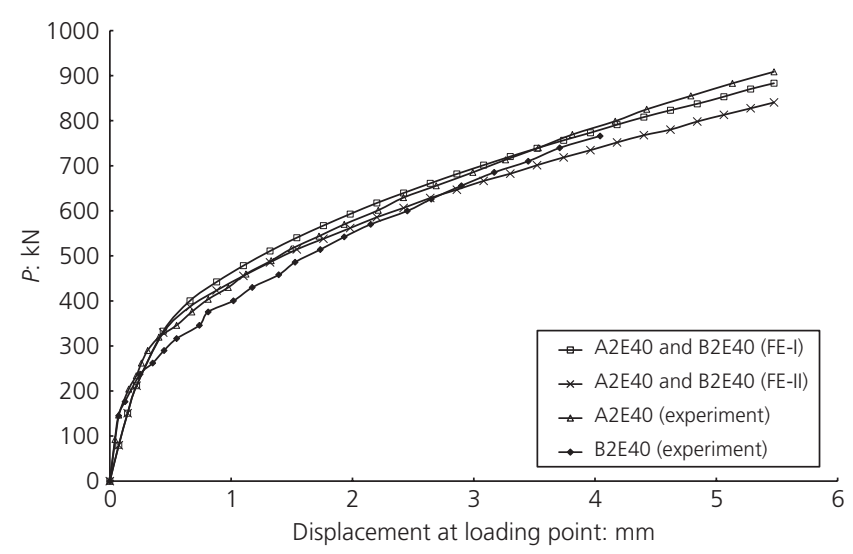

(e)

Figure 9. Load-displacement curves for specimens with two-ply FRP: (a) A2E0 and BE20; (b) A2E10 and B2E10; (c) A2E20 and B2E2O; (d) A2E30 and B2E30; (e) A2E40 and B2E40; (f) B2E50

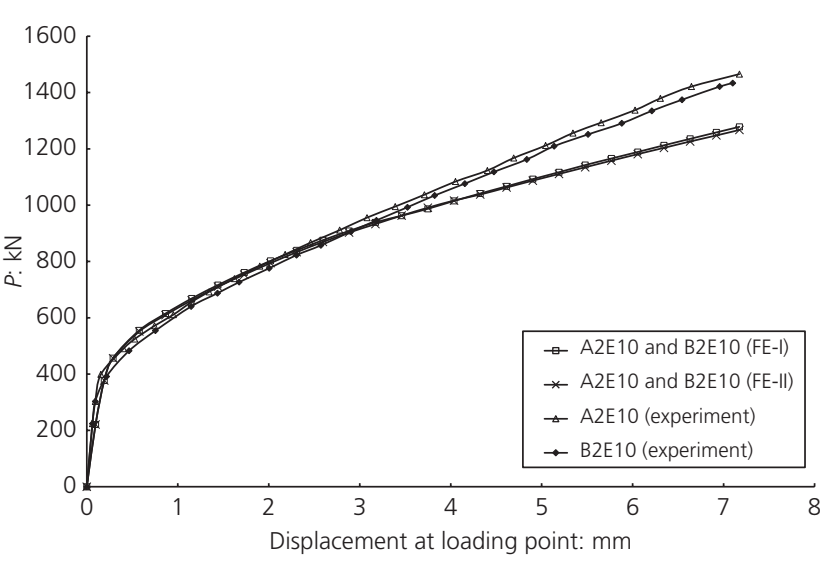

(b)

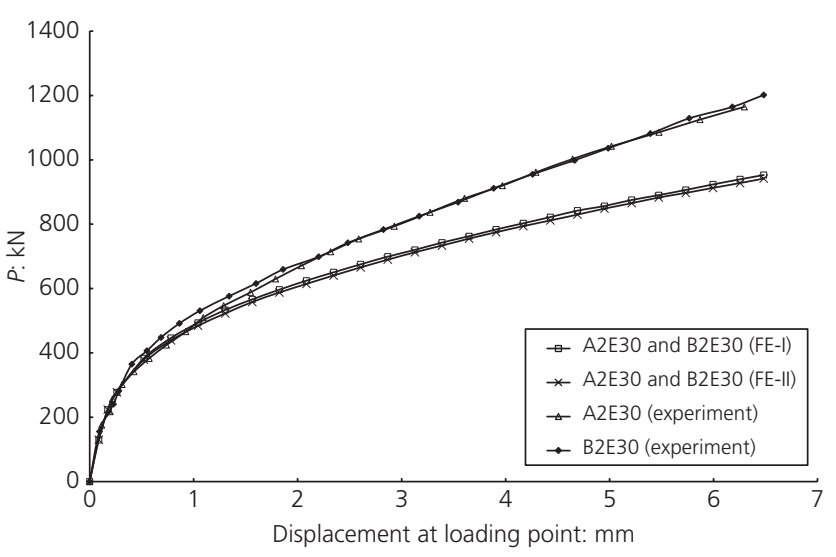

(d)

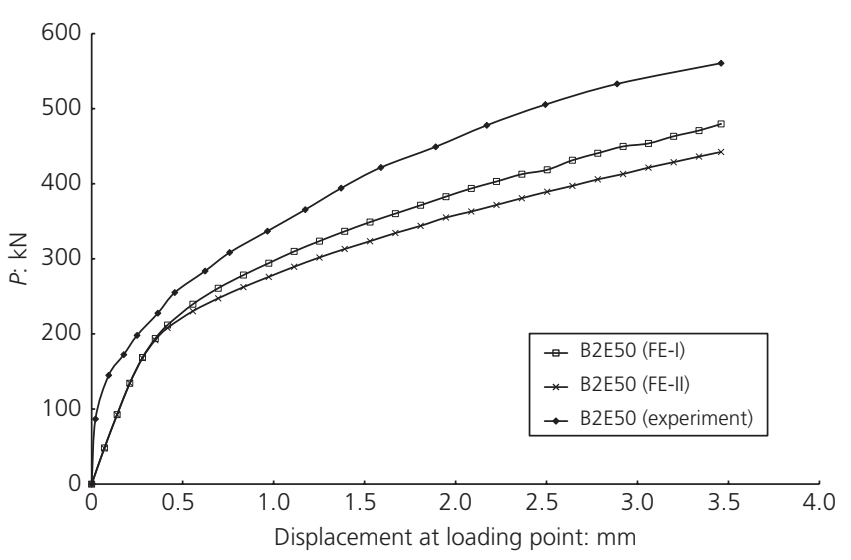

(f) two-ply), the FE analysis underestimates the loading by about $10-20 \%$ during the inelastic stage.

As the eccentricity $d_{\mathrm{e}}$ increased further, the differences between the FE analysis results and the experimental results reduced for most of the specimens. From Figures 8(e), 8(f) and
Figure 9(e), it is noted that for specimens A1E40 and B1E40 $\left(d_{\mathrm{e}}=40 \mathrm{~mm}\right.$, one-ply), B1E50 $\left(d_{\mathrm{e}}=50 \mathrm{~mm}\right.$, one-ply $)$ and A2E40 and B2E40 $\left(d_{\mathrm{e}}=40 \mathrm{~mm}\right.$, two-ply), the FE analysis results are in good agreement with the experimental counterparts, with errors mostly within $\pm 5 \%$. However, it is noted from Figure $9(\mathrm{f})$ that for specimen B2E50 $\left(d_{\mathrm{e}}=50 \mathrm{~mm}\right.$, 
two-ply), the FE-I and FE-II curves underestimate the loading by at most $14 \%$ and $21 \%$ during the inelastic stage, respectively.

The values of $P_{\mathrm{FE}-\mathrm{I}} / P_{\text {test }}$ and $P_{\mathrm{FE}-\mathrm{II}} / P_{\text {test }}$ for all 22 specimens analysed are given in Table 1; the respective mean values for these two sets of results were 0.90 and 0.88 and the respective coefficients of variation were $7 \cdot 1 \%$ and $7 \cdot 7 \%$. In order to determine how the difference between two different mesh densities applied in the FE analysis can be affected by the eccentricity of the loading, the percentage difference (PD) between $P_{\text {FE-I }} / P_{\text {test }}$ and $P_{\text {FE-II }} / P_{\text {test }}$ is defined as

22. $\mathrm{PD}=\frac{P_{\mathrm{FE}-\mathrm{I}}-P_{\mathrm{FE}-\mathrm{II}}}{P_{\text {test }}} \times 100$

which is correlated with $d_{\mathrm{e}} / D$ in Figure 10. It can be observed that PD is less than $1 \%$ for the axial loading case but, as $d_{\mathrm{e}} / D$ increases, the value of PD grows larger and larger due to the concentrations of the stress and the strain fields over the cross-sections. Therefore, a finer mesh is necessary for FE analysis on specimens with relatively large eccentricities, say $d_{\mathrm{e}} / D>0 \cdot 15$.

Although the FE analysis has a tendency to slightly underestimate the loading, the error is generally of the order of about $10 \%$. Hence, in terms of predicted loading, the proposed FE method should be regarded as reasonably accurate, given the complexity of the non-linear behaviour of FRP-confined concrete columns.

\subsection{Distributions of triaxial stresses over the sections}

In previous studies, the eccentric loading case has been analysed using the fibre element method (Lee et al., 2011; Liang,
2011) in which the non-uniform stress distributions are modelled in the form of parallel strips and the confining stresses within a single strip are assumed to be isotropic. However, from the present FE analysis (which should be more rigorous) it was observed that, under eccentric loading, the stress distributions are not in the form of parallel strips and the confining stresses are not isotropic, as shown in Figure 11. Moreover, to illustrate the distributions of axial stress over the cross-section, numerical results of the one-ply and the two-ply specimens with $d_{\mathrm{e}}=10 \mathrm{~mm}$ and $d_{\mathrm{e}}=50 \mathrm{~mm}$ when the displacement at the loading point is equal to $3.0 \mathrm{~mm}$ are plotted in Figure 12. All these results were achieved by FE analysis using the 6718element mesh.

When $d_{\mathrm{e}}=10 \mathrm{~mm}$, most of the concrete sections for both the one-ply and the two-ply specimens are subjected to $\sigma_{1}$ greater than $2.5 \mathrm{MPa}$ at a displacement of $3.0 \mathrm{~mm}$, as shown in Figures 11(a) and 11(b). In the same sections, the areas with $\sigma_{2}$ greater than $2.5 \mathrm{MPa}$ are slightly smaller than those of $\sigma_{2}$, as shown in Figures 11(c) and 11(d). It can be observed that, although the boundaries of different domains of stresses are irregular, the pattern of distribution is presented by definite layers of different colours, which is following the trend that the areas with higher axial compression normally possess larger values of $\sigma_{1}$ and $\sigma_{2}$. An exception was found in Figure 11(b), with $\sigma_{1}$ built up at the top zone of the half circular section.

Figures 12(a) and 12(b) illustrate that more than half of the concrete sections of the one-ply and the two-ply specimens with $d_{\mathrm{e}}=10 \mathrm{~mm}$ were subjected to an axial stress (i.e. $\sigma_{3}$ greater than $\left.1 \cdot 2 f_{\mathrm{c}}(36 \cdot 1 \mathrm{MPa})\right)$. Although the distribution patterns of the stresses for these two cases are similar, it is very

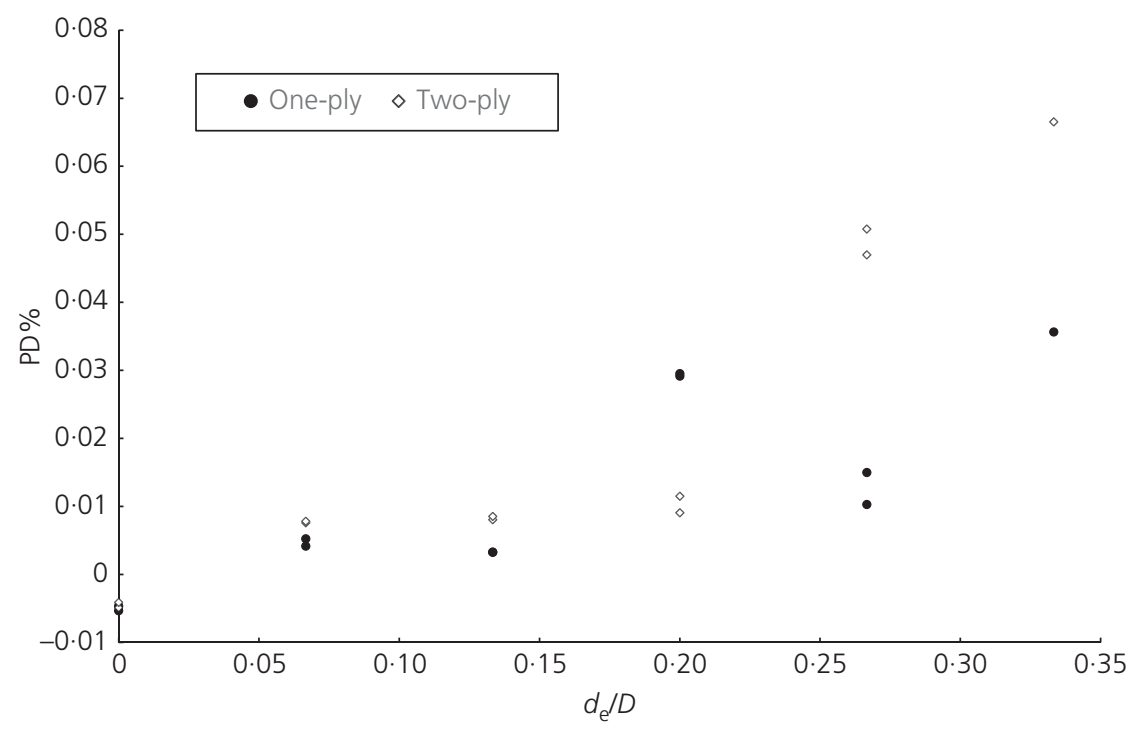

Figure 10. Percentage difference between the two meshes of 2203 and 6718 elements for one-ply and two-ply specimens 


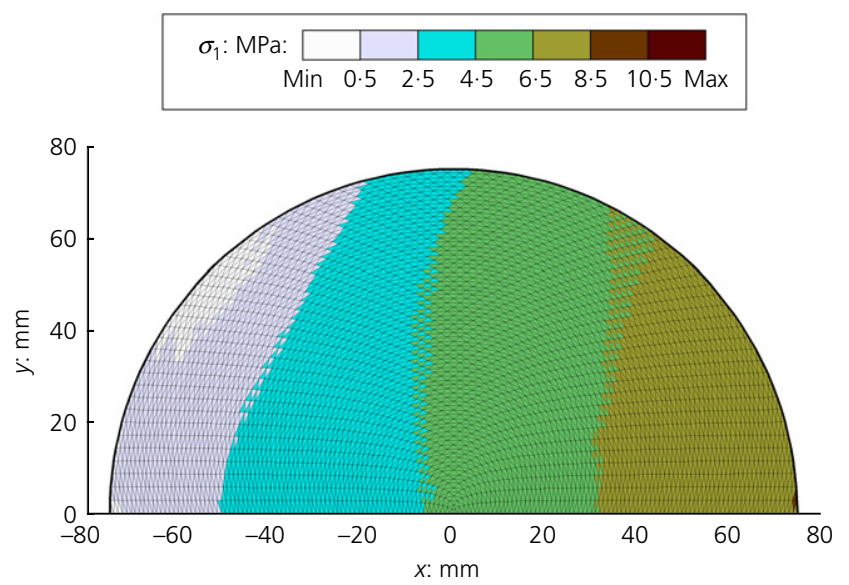

(a)
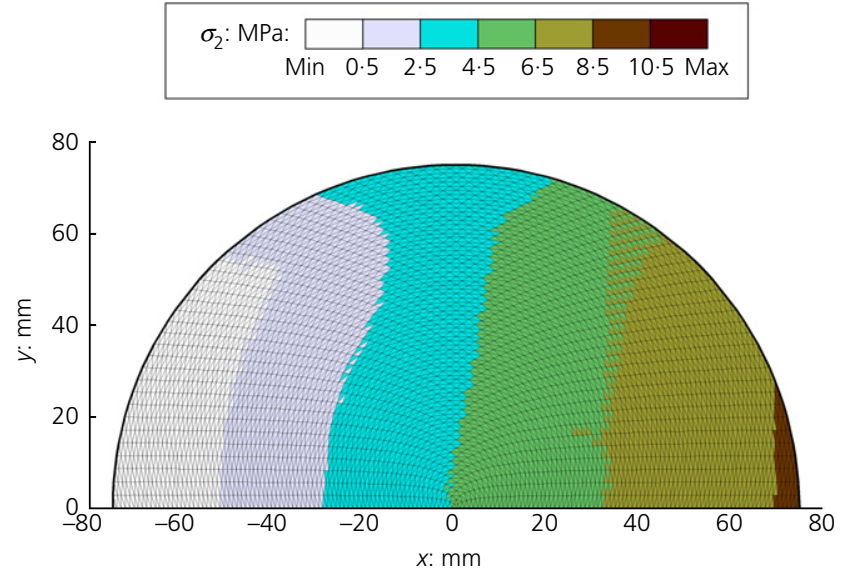

(c)

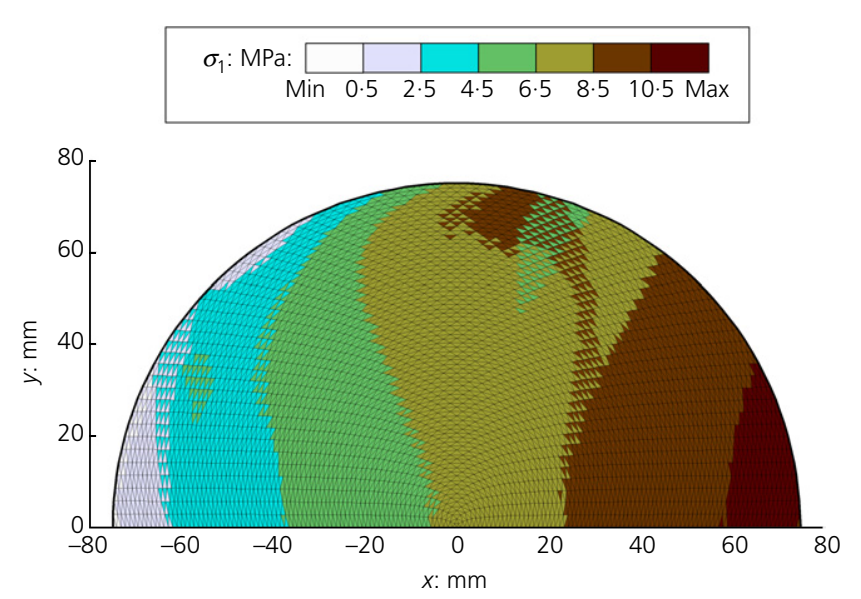

(b)

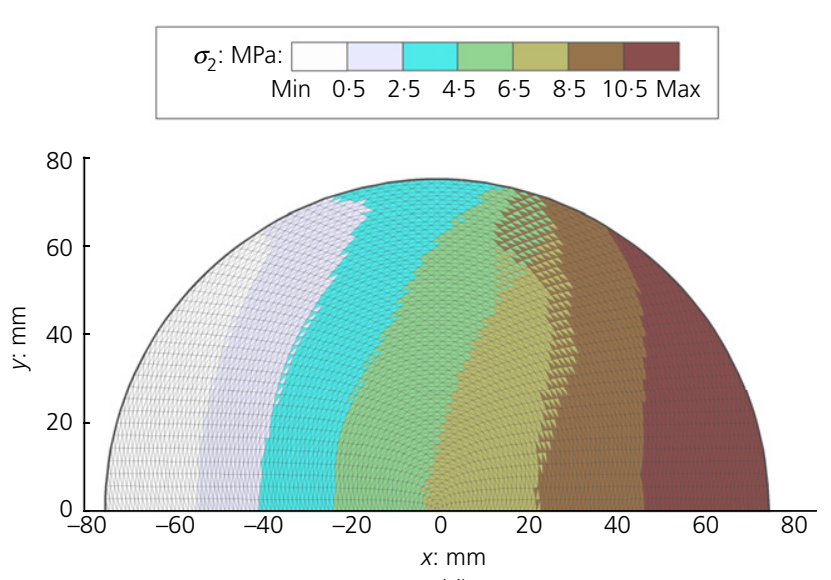

(d)

Figure 11. Distributions of (a) $\sigma_{1}$ (one-ply), (b) $\sigma_{1}$ (two-ply), (c) $\sigma_{2}$ (one-ply) and (d) $\sigma_{2}$ (two-ply) specimens with $d_{\mathrm{e}}=10 \mathrm{~mm}$ (displacement at loading point $=3.0 \mathrm{~mm}$ )

obvious that the magnitudes of the stresses in the two-ply section are significantly larger than those in the one-ply counterpart. However, for the cases of $d_{\mathrm{e}}=50 \mathrm{~mm}$ displayed in Figures 12(c) and 12(d), both the distributions and magnitudes of $\sigma_{3}$ in the two sections bear decent resemblance, and the areas with $\sigma_{3}>36 \cdot 1 \mathrm{MPa}$ are all localised to the most compressive ends of the sections.

It was mentioned in Section 2.3 that the effective value of $f_{\mathrm{r}}$ is determined by $f_{\mathrm{r}}=\min \left\{\sigma_{1}, \sigma_{2}\right\}$; the variations of $f_{\mathrm{r}}$ along with the displacement at the loading point for two-ply specimens with $d_{\mathrm{e}}=10 \mathrm{~mm}$ and $50 \mathrm{~mm}$ are shown in Figure 13. The magnitudes of $f_{\mathrm{r}}$ keep increasing as the displacement grows, and their distribution patterns are similar to those displayed in Figures 11 and 12, but with more regular curved boundaries between layers of different colours.
To further study how the confining stresses vary with the eccentricity, the average confining stress $f_{\mathrm{r} \text {,avg }}$ was determined as

23. $f_{\mathrm{r}, \mathrm{avg}}=\frac{\sum_{i=1}^{n}\left(f_{\mathrm{r}, i} \cdot A_{i}\right)}{A_{\mathrm{c}}}$

where $n$ is the total number of concrete elements, $A_{i}$ is the area of the element $i$ and $A_{\mathrm{c}}$ is the total area of the concrete section. The average confining stress so determined at each loading step is plotted against the displacement for the different specimens with different eccentricities in Figure 14. It is obvious from the figure that the average confining stress increases as the displacement increases but its value is generally lower at a larger eccentricity. This also means that in the design of FRP-confined columns under eccentric loading, thicker FRP wraps have to be used to attain the same level of 


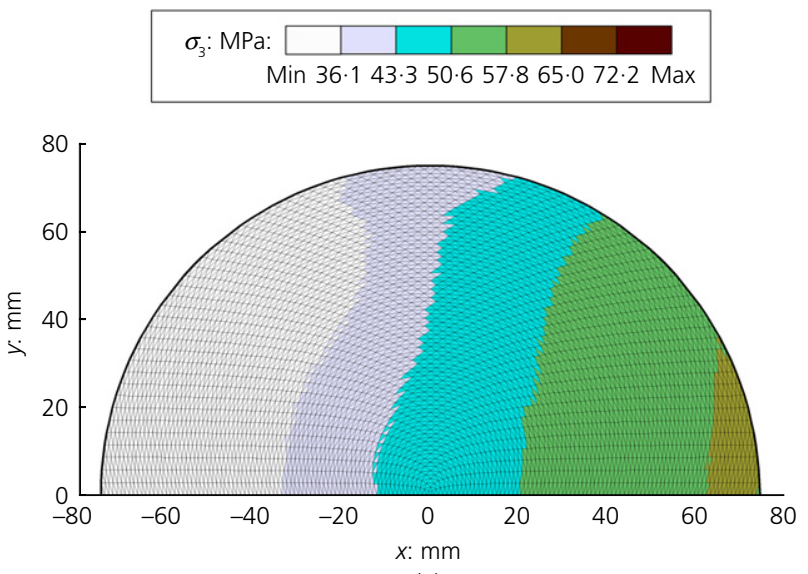

(a)
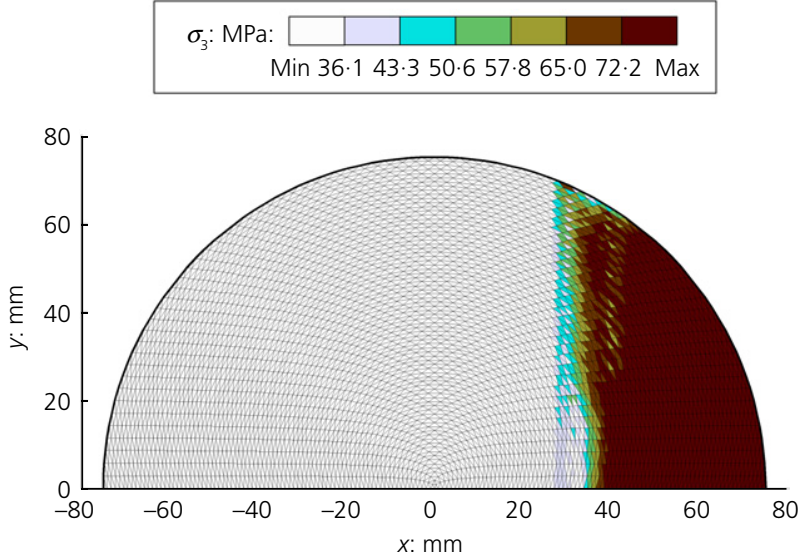

(c)

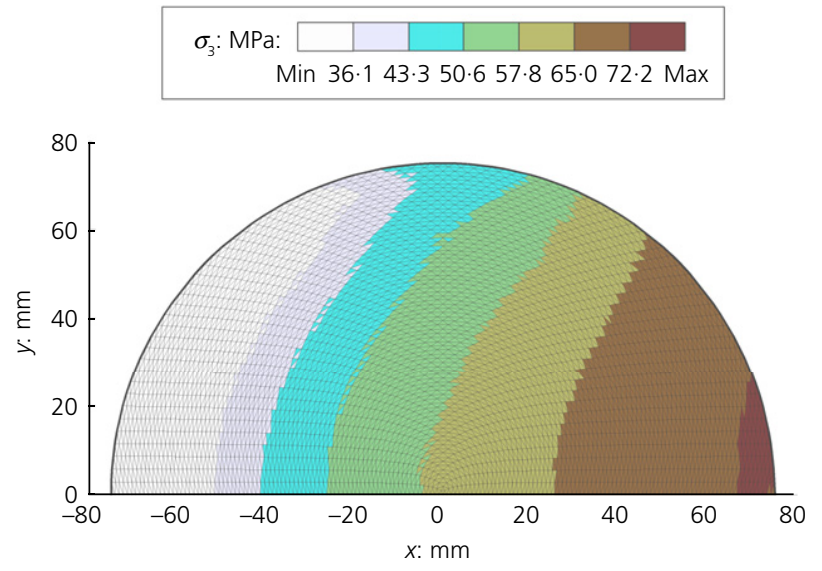

(b)
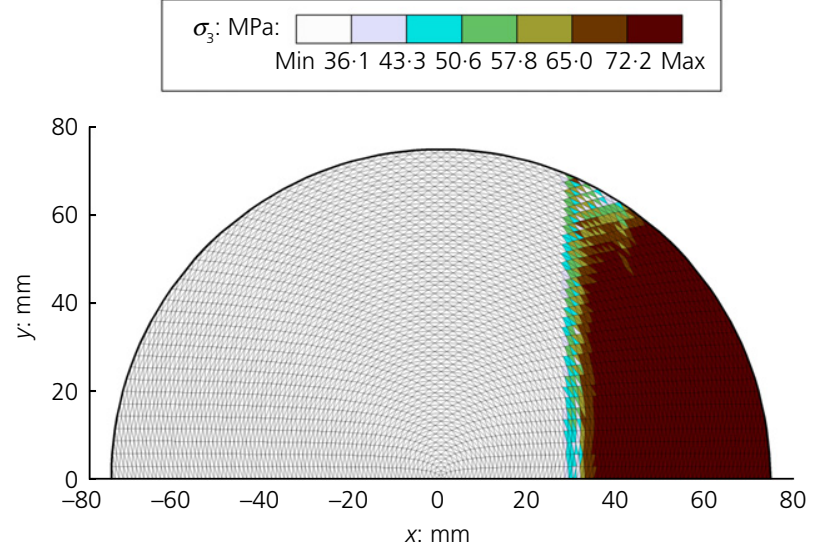

(d)

Figure 12. Distribution of $\sigma_{3}$ : (a) $d_{\mathrm{e}}=10 \mathrm{~mm}$, one-ply;

(b) $d_{\mathrm{e}}=10 \mathrm{~mm}$, two-ply; (c) $d_{\mathrm{e}}=50 \mathrm{~mm}$, one-ply; (d) $d_{\mathrm{e}}=50 \mathrm{~mm}$, two-ply (displacement at loading point $=3.0 \mathrm{~mm}$ )

confinement at larger eccentricity. Another important observation is that one more layer of FRP will let the value of $f_{\mathrm{r} \text {,avg }}$ increase from $4.2 \mathrm{MPa}$ to $6.5 \mathrm{MPa}$ at a displacement of $3.0 \mathrm{~mm}$ for specimens under concentric loading, whereas there is not much of a difference (2.4 MPa for one-ply and 2.6 MPa for two-ply) for specimens with $d_{\mathrm{e}}=40 \mathrm{~mm}$. In other words, FRP wraps are less effective under eccentric loading than concentric loading.

\section{Conclusions}

In order to evaluate non-uniform and anisotropic confining stresses in confined concrete and study the full-range nonlinear behaviour of confined concrete columns, a new FE analysis method was developed by integrating the lateral strain-axial strain model of Dong et al. (2015a), the triaxial failure surface of Menétrey and Willam (1995), the axial stress-strain model of Attard and Setunge (1996) and the strain gradient model developed by Ho and Peng (2013) and treating the analysis of the biaxial confining stresses in the concrete section as a $2 \mathrm{D}$ analysis problem. In theory, the new FE analysis method should be applicable to confined concrete columns of any shape and under any combination of axial load and bending moment, but, as a start, it was applied in this paper only to FRP-confined concrete columns of circular shape and under eccentric loading.

To verify the applicability and accuracy of the newly developed FE analysis method, 22 specimens of FRP-confined circular concrete columns tested under eccentric loading by $\mathrm{Wu}$ and Jiang (2013) were analysed and two sets of numerical results obtained by the FE analysis implementing different meshes (a 2203-element mesh and a 6718-element mesh) were compared with the corresponding experimental results. It was found that a high-density mesh is necessary when a large eccentricity is present in the load case due to the concentration of strains and stresses over the section. Overall, the loads predicted by the 


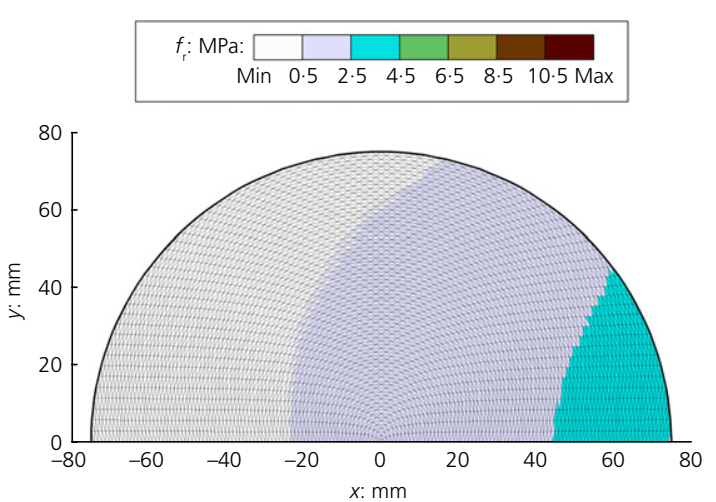

(a)

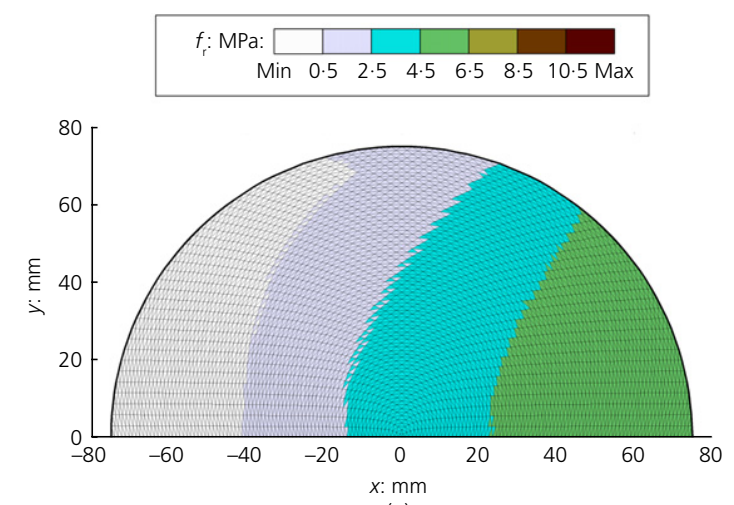

(c)

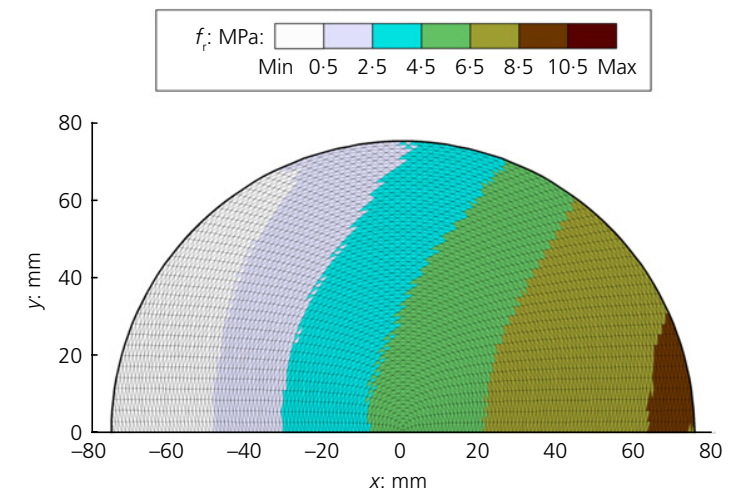

(e)

Figure 13. Variation of $f_{\mathrm{r}}$ for two-ply specimens:

(a) $d_{\mathrm{e}}=10 \mathrm{~mm}$ and (b) $d_{\mathrm{e}}=50 \mathrm{~mm}$ with displacement at loading point $=0.75 \mathrm{~mm}$; (c) $d_{\mathrm{e}}=10 \mathrm{~mm}$ and (d) $d_{\mathrm{e}}=50 \mathrm{~mm}$ with displacement at loading point $=1.5 \mathrm{~mm}$; (e) $d_{\mathrm{e}}=10 \mathrm{~mm}$ and

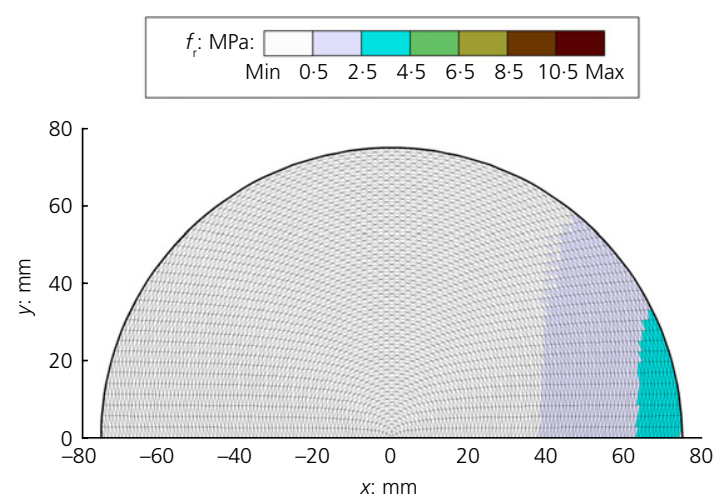

(b)

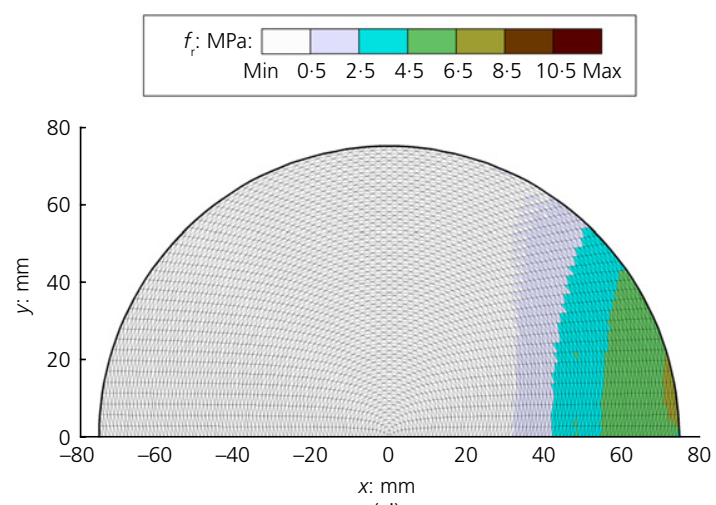

(d)

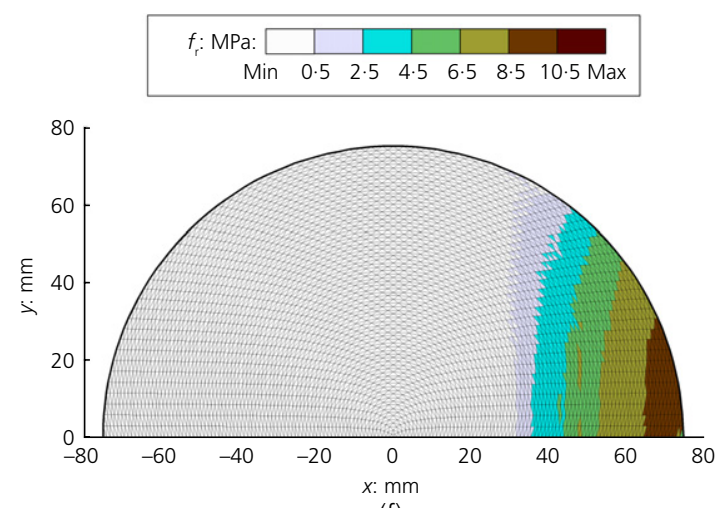

(f)

(f) $d_{\mathrm{e}}=50 \mathrm{~mm}$ with displacement at loading point $=2.25 \mathrm{~mm}$; (g) $d_{\mathrm{e}}=10 \mathrm{~mm}$ and $(\mathrm{h}) d_{\mathrm{e}}=50 \mathrm{~mm}$ with displacement at loading point $=3.0 \mathrm{~mm}$ (continued on next page)
FE analysis agreed quite well with the experimental results, the respective mean values for $P_{\mathrm{FE}-\mathrm{I}} / P_{\text {test }}$ and $P_{\mathrm{FE}-\mathrm{II}} / P_{\text {test }}$ equal to 0.90 and 0.88 and corresponding coefficients of variance equal to $7 \cdot 1 \%$ and $7 \cdot 7 \%$.

The FE analysis results revealed that, for FRP-confined circular concrete columns under eccentric loading, the confining stresses are far from being uniform or isotropic. Hence, the previously developed formulas and models for evaluation of confining stresses, which assume that the confining stresses are uniform and isotropic, are not generally applicable. Moreover, the axial stress distribution is very different from the axial strain distribution and therefore has to be analysed as an integral part of the theoretical analysis. Lastly, the FE results also revealed that the average confining stress in the section decreases as the eccentricity of the loading increases. Hence, FRP wraps are less effective under eccentric loading than concentric loading. 


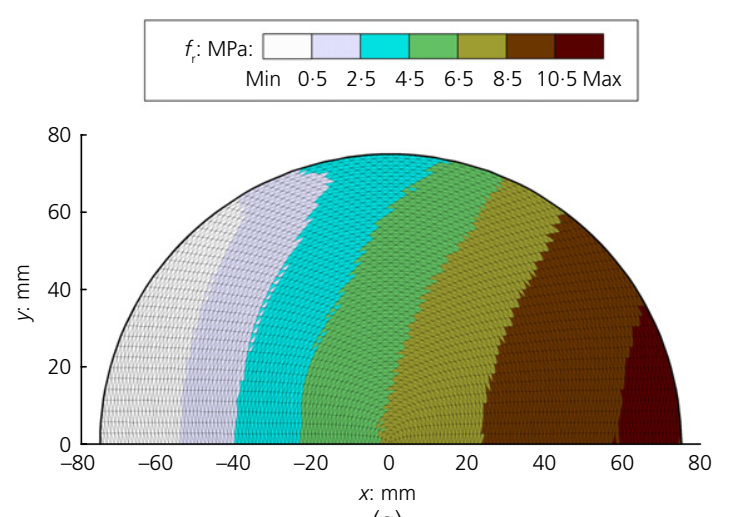

(g)

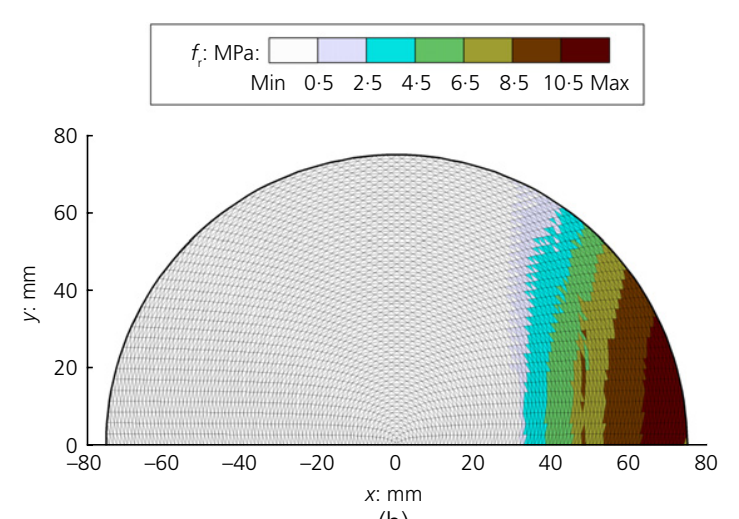

(h)

Figure 13. Continued

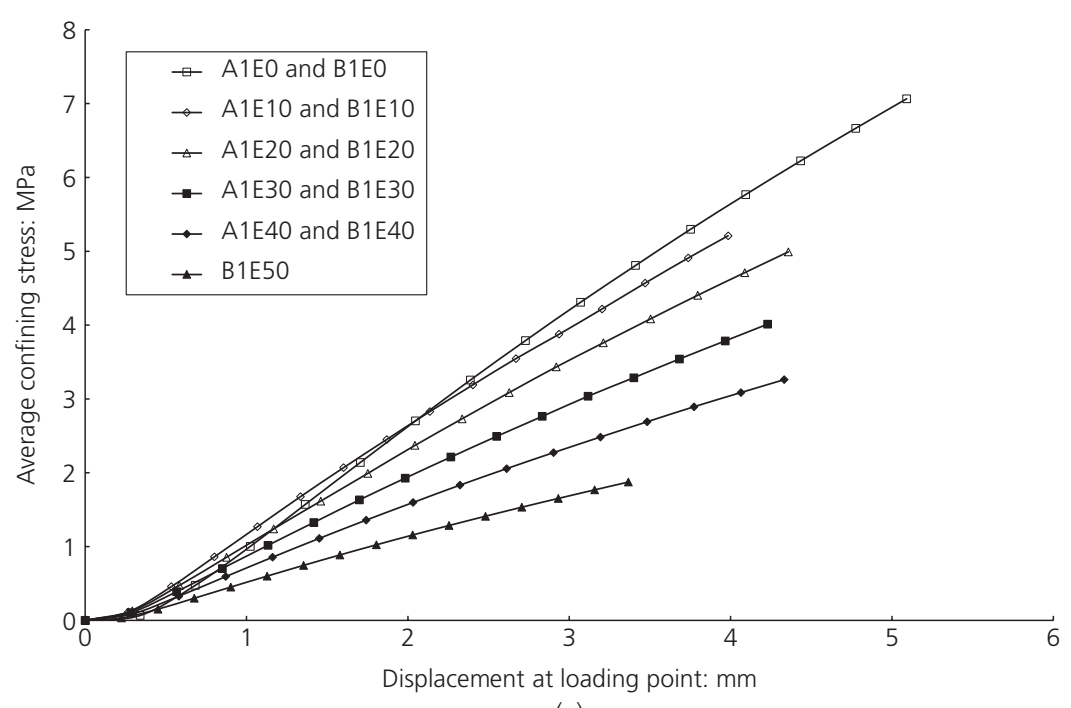

(a)

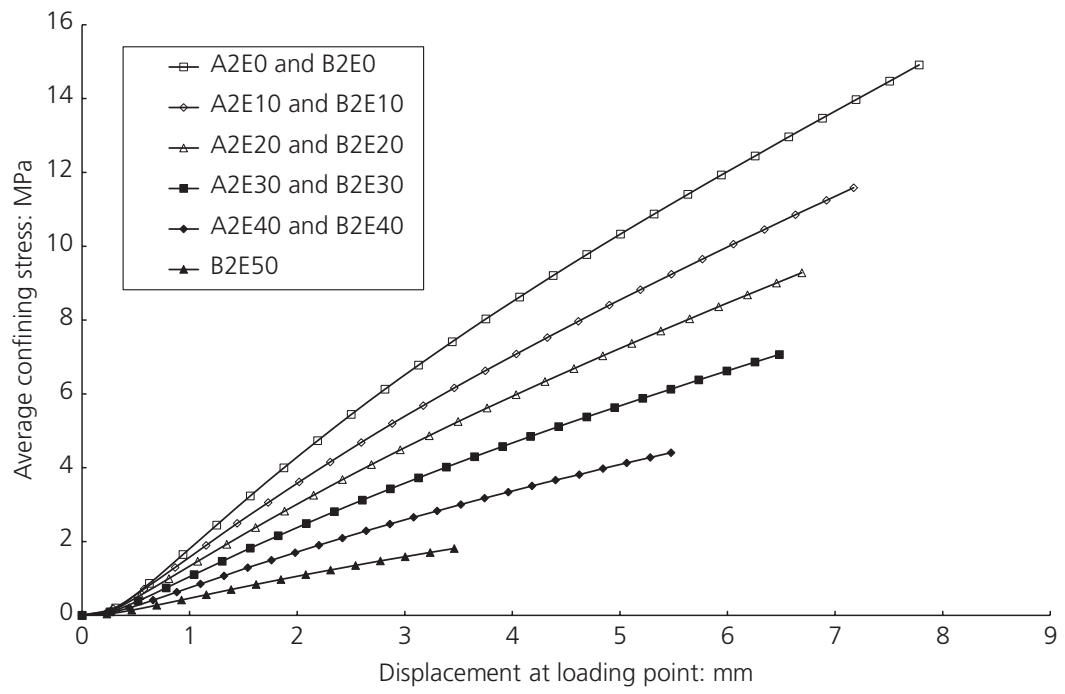

(b)

Figure 14. Relationship between average confining stress and load eccentricity 


\section{REFERENCES}

Attard MM and Setunge S (1996) Stress-strain relationship of confined and unconfined concrete. ACI Materials Journal 93(5): 432-441.

Carrasquillo RL, Slate FO and Nilson AH (1981) Properties of high-strength concrete subject to short-term loads. $A C I$ Journal 78(3): 171-178.

Chen MT and Ho JCM (2015) Concurrent flexural strength and ductility design of $\mathrm{RC}$ beams via strain-gradient-dependent concrete stress-strain curve. The Structural Design of Tall and Special Buildings 24(9): 629-652.

Dong CX, Kwan AKH and Ho JCM (2015a) A constitutive model for predicting the lateral strain of confined concrete. Engineering Structures 91: 155-166.

Dong CX, Kwan AKH and Ho JCM (2015b) Effects of confining stiffness and rupture strain on performance of FRP confined concrete. Engineering Structures 97: 1-14.

Fam AZ and Rizkalla SH (2001) Confinement model for axially loaded concrete confined by circular fiberreinforced polymer tubes. ACI Structural Journal 98(4): 451-461.

Harries KA and Kharel G (2002) Behavior and modeling of concrete subject to variable confining pressure. $A C I$ Materials Journal 99(2): 180-189.

Ho JCM and Peng J (2013) Strain-gradient-dependent stressstrain curve for normal-strength concrete. Advances in Structural Engineering 16(11): 1911-1930.

Ho JCM, Kwan AKH and Pam HJ (2003) Theoretical analysis of post-peak flexural behavior of normal- and high-strength concrete beams. The Structural Design of Tall and Special Buildings 12(2): 109-125.

Ho JCM, Lam JYK and Kwan AKH (2010) Effectiveness of adding confinement for ductility improvement of highstrength concrete columns. Engineering Structures 32(3): 714-725.

Hu B (2013) An improved criterion for sufficiently/insufficiently FRP-confined concrete derived from ultimate axial stress. Engineering Structures 46: 431-446.

Hu B, Wang JG and Li GQ (2011) Numerical simulation and strength models of FRP-wrapped reinforced concrete columns under eccentric loading. Construction and Building Materials 25(5): 2751-2763.

Hu HT, Huang CS, Wu MH and Wu WM (2003) Nonlinear analysis of axially loaded concrete-filled tube columns with confinement effect. Journal of Structural Engineering, ASCE 129(10): 1322-1329.

Imran I and Pantazopoulou SJ (1996) Experimental study of plain concrete under triaxial stress. ACI Materials Journal 93(6): 589-601.

Jiang T and Teng JG (2007) Analysis-oriented stress-strain models for FRP-confined concrete. Engineering Structures 29(11): 2968-2986.

Kwan AKH, Dong CX and Ho JCM (2015) Axial and lateral stress-strain model for FRP confined concrete. Engineering Structures 99: 285-295.
Kwan KH and Liauw TC (1985) Computerized ultimate strength analysis of reinforced concrete sections subjected to axial compression and biaxial bending. The Structural Engineer 21(6): 1119-1127.

Lam L and Teng JG (2002) Strength models for fiber-reinforced plastic-confined concrete. Journal of Structural Engineering, ASCE 128(5): 612-623.

Lee SH, Uy B, Kim SH, Choi YH and Choi SM (2011) Behavior of high-strength circular concrete-filled steel tubular (CFST) column under eccentric loading. Journal of Constructional Steel Research 67(1): 1-13.

Liang QQ and Fragomeni S (2010) Nonlinear analysis of circular concrete-filled steel tubular short columns under eccentric loading. Journal of Constructional Steel Research 66(2): 159-169.

Liang QQ (2011) High strength circular concrete-filled steel tubular slender beam-columns, part I: numerical analysis. Journal of Constructional Steel Research 67(2): 164-171.

Lo SH, Kwan AKH, Ouyang Y and Ho JCM (2015) Finite element analysis of axially loaded FRP-confined rectangular concrete columns. Engineering Structures 100(1): 253-263.

Mander JB, Priestly JN and Park R (1988) Theoretical stressstrain model for confined concrete. Journal of Structural Engineering, ASCE 114(8): 1804-1826.

Menétrey P and Willam KJ (1995) Triaxial failure criterion for concrete and its generalization. ACI Structural Journal 92(3): 311-318.

Mirmiran A and Shahawy M (1997) Dilation characteristics of confined concrete. Mechanics of Cohesive-Frictional Materials 2(3): 237-249.

Mirmiran A, Zagers K and Yuan WQ (2000) Nonlinear finite element modeling of concrete confined by fiber composites. Finite Elements in Analysis and Design 35: 79-96.

Ozbakkaloglu T, Lim JC and Vincent T (2013) FRP-confined concrete in circular sections: review and assessment of stress-strain models. Engineering Structures 49: 1068-1088.

Papanikolaou VK and Kappos AJ (2007) Confinement-sensitive plasticity constitutive model for concrete in triaxial compression. International Journal of Solids and Structures 44(21): 7021-7048.

Popovics S (1973) Numerical approach to the complete stressstrain relation for concrete. Cement and Concrete Research 3(5): 583-599.

Saadatmanesh H, Ehsani MR and Li MW (1994) Strength and ductility of concrete columns externally confined with fiber composite straps. ACI Structural Journal 94(1): 434-447.

Saenz LP (1964) Discussion of 'Equation for the stress-strain curve of concrete' by P. Desayi, and S. Krishnan. ACI Journal 61(9): 1229-1235.

Tao Z, Wang ZB and Yu Q (2013) Finite element modelling of concrete-filled steel stub columns under axial compression. Journal of Constructional Steel Research 89: 121-131.

Teng JG and Lam L (2004) Behavior and modeling of fiber reinforced polymer-confined concrete. Journal of Structural Engineering, ASCE 130(11): 1713-1723. 
Teng JG, Huang YL, Lam L and Ye LP (2007) Theoretical model for fiber reinforced polymer-confined concrete. Journal of Composites for Construction, ASCE 11(2): 202-210.

Wu YF and Jiang C (2013) Effect of load eccentricity on the stress-strain relationship of FRP-confined concrete columns. Composite Structures 98: 228-241.
Yu T, Teng JG, Wong YL and Dong SL (2010a) Finite element modeling of confined concrete-I: Drucker-Prager type plasticity model. Engineering Structures 32(3): 665-679.

Yu T, Teng JG, Wong YL and Dong SL (2010b) Finite element modeling of confined concrete-II: plastic-damage model. Engineering Structures 32(3): 680-691.

\section{HOW CAN YOU CONTRIBUTE?}

To discuss this paper, please email up to 500 words to the editor at journals@ice.org.uk. Your contribution will be forwarded to the author(s) for a reply and, if considered appropriate by the editorial board, it will be published as discussion in a future issue of the journal.

Proceedings journals rely entirely on contributions from the civil engineering profession (and allied disciplines). Information about how to submit your paper online is available at www.icevirtuallibrary.com/page/authors, where you will also find detailed author guidelines. 